\title{
Impulsive Behavior in Competition: Testing Theories of Overbidding in Rent-Seeking Contests
}

\author{
Roman M. Sheremeta ${ }^{a, b, *}$ \\ ${ }^{\text {a }}$ Weatherhead School of Management, Case Western Reserve University \\ 11119 Bellflower Road, Cleveland, OH 44106, USA \\ ${ }^{\mathrm{b}}$ Economic Science Institute, Chapman University \\ One University Drive, Orange, CA 92866, USA
}

September 14, 2016

\begin{abstract}
Researchers have proposed various theories to explain overbidding in rentseeking contents, including mistakes, systematic biases, the utility of winning, and relative payoff maximization. Through an eight-part experiment, we test and find significant support for the existing theories. Also, we discover some new explanations based on cognitive ability and impulsive behavior. Out of all explanations examined, we find that impulsivity is the most important factor explaining overbidding in contests.
\end{abstract}

JEL Classifications: C72, C91, D01, D72

Keywords: rent-seeking, contest, competition, impulsive behavior, experiments

* Corresponding author: Roman Sheremeta, rms246@ case.edu and rshereme@ gmail.com I have benefitted from the helpful comments of Loukas Balafoutas, Tim Cason, David Clingingsmith, Cary Deck, Gerald Eisenkopf, Urs Fishbacher, David Gill, Erik Kimbrough, Florian Lindner, John List, Klaus Schmidt, Scott Shane, Charles Sprenger, Rudi Stracke, Uwe Sunde and seminar participants at Case Western Reserve University, Oberlin College, Monash University, the University of Konstanz, the University of Munich, the University of Innsbruck, as well as participants at the North American Economic Science Association Meetings in Dallas and the Economics and Biology of Contests Conference in Brisbane. I remain solely responsible for any errors or omissions. 


\section{Introduction}

Competition in its pure form is a contest between individuals for a reward which can be material, such as resources and goods, or non-material, such as prestige and fame. It occurs when individual interests are misaligned and when resources are limited. People compete on a daily basis by trying to secure better jobs, bargaining at the marketplace, or engaging in competitive sports. Although some competition can be beneficial, encouraging innovation (Schumpeter, 1942; Terwiesch and $\mathrm{Xu}, 2008$ ) and efficient allocation of resources (Smith, 1962; Fama, 1970; Arrow, 1974), overly competitive behavior can be destructive.

One prominent example of overly competitive behavior leading to inefficient outcomes is rent-seeking contests (Krueger, 1974; Tullock, 1980). In such contests, firms or individuals engage in unproductive competition in order to increase one's share of existing wealth without creating new wealth. For example, a firm may choose to spend money on lobbying for government to impose regulations on competitors in order to increase market share. Such competitive behavior is costly, but it creates no value. Theoretical models of rent-seeking predict substantial welfare losses resulting from inefficient competition (see the review by Konrad, 2009). Empirical studies suggest that the actual costs of rent-seeking are very high (see the review by Del Rosal, 2011). To provide some examples, Krueger (1974) calculates that $7 \%$ of India's 1964 and 15\% of Turkey's 1968 gross national product were wasted in rent-seeking activities. However, the exact amount of welfare losses is highly sensitive to the empirical strategy used to estimate such losses. ${ }^{1}$ Therefore, many researches conduct laboratory

\footnotetext{
${ }^{1}$ Posner (1975) uses industry sales to estimate that the rent-seeking costs may range from 5\% to $32 \%$ of all industry sales. Laband and Sophocleus (1992) use indirect measures of rent-seeking and find that the cost of rent-seeking in the US was about $23 \%$ of 1985 gross national product. Mauro (1995) uses corruption as a proxy for rent-seeking to show how it is detrimental to economic growth.
} 
experiments (see the review by Dechenaux et al., 2015), which allow a more direct measure of rent-seeking. $^{2}$

Consider the following experiment. You are competing against an opponent in a lottery contest for a prize of $\$ 100$. The probability of winning equals the ratio of your bid to the sum of your and the opponent's bids, and all bids are forgone. While the intuitive choice may be to bid $\$ 50$ (half of the prize), more deliberate consideration will show that any bid above $\$ 25$ is strictly dominated, indicating that you should never bid more than $\$ 25 .{ }^{3}$ Despite such predictions the vast majority of participants in rent-seeking contest experiments routinely overbid by choosing strictly dominated strategies (Dechenaux et al., 2015), creating a puzzle for economists. In many studies, overbidding is so high that participants receive negative expected payoffs. ${ }^{4}$ Various theories have been proposed to explain this phenomenon, including mistakes, systematic biases, the utility of winning, and relative payoff maximization (see the reviews by Sheremeta, 2013, 2015). However, some of these theories have not been tested, and no attempt has been made to examine the possible links between different explanations.

The purpose of this paper is to simultaneously test different theories of overbidding and to provide a unified explanation for overbidding in rent-seeking contests. To accomplish this, we conduct an eight-part experiment. The key innovation of our paper is that we study simultaneously all major existing, as well as some new theories of overbidding in the same group of subjects. This has a number of advantages. First, we test different theories on the same dataset.

\footnotetext{
${ }^{2}$ Experiments, of course, trade external validity for internal validity, thus raising questions about the generalizability but providing high accuracy in measuring specific outcomes (Cook et al., 1979).

${ }^{3}$ The working version of this paper has been presented at more than half a dozen universities. When asked the same question, a very common response from full time faculty was to bid $\$ 50$. A bid equal to the half of the prize is an intuitive response often chosen by many subjects in lottery contest experiments (Chowdhury et al., 2014; Lacomba et al., 2014; Lim et al., 2014). We also find in our experiment that bidding half of the prize is one of the most commonly used strategies by participants.

${ }^{4}$ Here the welfare losses from rent seeking are born by the rent seekers themselves. However, in other cases of rentseeking, in particular, in the case of the imposition of regulations on competitors, the welfare losses are incurred both by customers and the competitor firms.
} 
Second, we can examine the relationship between different factors contributing to the same overbidding phenomenon. Third, we are able to control for some factors while examining the relationship between others. Finally, we can estimate the relative importance of each explanatory factor, allowing us to evaluate which factors are most important in explaining overbidding.

Our empirical findings can be summarized as follows. First, we find significant support for the existing theories of overbidding. For example, we show that participants who better understand the rules of the rent-seeking contest overbid less, suggesting that mistakes could be one of the reasons for overbidding. Related to mistakes, we find that behavior in contests is driven by systematic biases grounded in prospect theory. Also, we provide evidence that participants care not only about the prize, but also about winning itself, and such non-monetary utility of winning could partially explain overbidding.

Second, besides the existing theories of overbidding, we discover some new explanations. For example, we show that participants who display competitive preferences (in a separate task) by choosing to sacrifice social welfare to have a higher payoff than others choose significantly higher bids than participants with prosocial preferences. This suggests that bidding is a competitive phenomenon. Also, we find that participants who have lower cognitive ability, measured through a cognitive test based on the Graduate Record Examination, make significantly higher bids. This suggests that overbidding in rent-seeking contests is driven in part by limited cognitive ability.

Third, out of all explanations examined, we find that impulsivity, measured through a Cognitive Reflection Test, is the most important factor explaining overbidding in rent-seeking contests. Impulsivity is also correlated with competitive preferences and cognitive ability, as well as the utility of winning. However, when putting together in a joint multivariate analysis, only 
impulsivity remains significant, suggesting that overbidding is primarily driven by impulsive behavior.

We describe the theoretical model of rent-seeking in Section 2. The experimental design and procedures are described in Section 3. Our main results are presented in Section 4, along with sub-sections focusing on different parts of the data. We discuss implications of our results in Section 5.

\section{Theoretical Model}

Consider a simple rent-seeking contest of Tullock (1980) in which two individuals compete for a prize value of $v$. The probability that individual $i$ wins the prize depends on individual $i$ 's bid $b_{i}$ relative to individual $j$ 's bid $b_{j}$, and it is defined by a lottery contest success function:

$$
p_{i}\left(b_{i}, b_{j}\right)=b_{i} /\left(b_{i}+b_{j}\right)
$$

If $b_{i}=b_{j}=0$ then $p_{i}\left(b_{i}, b_{j}\right)=1 / 2$. The expected payoff for individual $i$ is equal to the probability of winning the prize $p_{i}\left(b_{i}, b_{j}\right)$ times the prize value $v$ minus the cost of bid $b_{i}$, plus the probability of losing times the cost of bid:

$$
\pi_{i}\left(b_{i}, b_{j}\right)=p_{i}\left(b_{i}, b_{j}\right)\left(v-b_{i}\right)+\left(1-p_{i}\left(b_{i}, b_{j}\right)\right)\left(-b_{i}\right)
$$

Differentiating (2) with respect to $b_{i}$ gives the following best-response function for individual $i$ (similarly individual $j$ ):

$$
b_{i}\left(b_{j}\right)=\sqrt{v b_{j}}-b_{j}
$$

By solving best-response functions $b_{i}\left(b_{j}\right)$ and $b_{j}\left(b_{i}\right)$ simultaneously, we receive equilibrium bids

$$
b_{i}^{*}=b_{j}^{*}=b^{*}=v / 4 .
$$


The symmetric pure-strategy Nash equilibrium (4) is unique and there are no asymmetric or mixed-strategy equilibria (Szidarovszky and Okuguchi, 1997). Moreover, bids higher than $b^{*}$ are strictly dominated and therefore should not be chosen by rational economic agents (note that the best-response function (3) reaches its maximum at $v / 4$ given any positive bid $b_{j}$ ).

Despite such stark predictions, the vast majority of participants in rent-seeking contest experiments overbid relative to the Nash equilibrium. Sheremeta (2013) examines a sample of 30 contest experiments and finds that the median overbidding rate is $72 \%$. The magnitude of overbidding is so high that many participants receive negative expected payoffs (Abbink et al., 2010; Price and Sheremeta, 2011, 2015; Chowdhury et al., 2014; Lim et al., 2014; Mago et al., 2016). To explain such behavior a number of theories have been proposed, including mistakes, systematic biases, the utility of winning, and relative payoff maximization. Although some of these theories found empirical support in the literature, their relative impact on individual behavior remains unknown. It is possible that some of the factors contributing to overbidding are correlated. For example, the utility of winning may be driven by relative payoff maximization, or systematic biases may be driven by mistakes. Moreover, it is an open question as to whether there is an underling theory which potentially could unify all of the existing explanations of overbidding. To answer these questions, we conduct a controlled laboratory experiment.

\section{Experimental Design and Procedures}

In order to test different theories of overbidding, we collected data on a number of different economic behaviors. The data came from a computerized experiment (Fischbacher, 2007), conducted at the Economic Science Institute laboratory. A total of 184 undergraduate students participated in 11 experimental sessions. Each session lasting between 70 and 90 
minutes had between 16 and 24 participants. The currency used in the experiment was U.S. Dollars. Upon completion of the experiment, earnings from the experiment were added to a participation fee of $\$ 10$. Participants received their payments in private and in cash, ranging from $\$ 7.50$ to $\$ 33$.

The experiment proceeded in eight parts, summarized in Table 1. Participants were told that there would be eight independent parts and that the new set of instructions (available in Appendix A) would be given to them at the beginning of each part. The experimenter read the instructions for each part aloud. In part 1, participants were given the instructions explaining the rules of a simple two-player lottery contest. Each participant was randomly and anonymously matched with another participant. Both matched participants could bid for a reward of $\$ 8$ by choosing any number between $\$ 0$ and $\$ 10$ (including increments of $\$ 0.25$ ). Instructions clearly stated that regardless of who receives the reward, both participants would have to pay their bids and that they could receive negative earnings that would be subtracted from their participation fee. After reading the instructions, but before making their decisions, participants completed an incentivized quiz on the computer to verify their understanding of the game. Participants had 5 minutes to answer 5 quiz questions, and they received $\$ 0.50$ for each correct answer. After answering all quiz questions, participants were asked to submit their bids. The computer chose the winner by implementing a simple lottery rule: the probability of receiving the reward was calculated as the number of dollars a participant bids divided by the total number of dollars both participants bid. However, the results of this part of the experiment were not presented until the very end of the experiment, after all parts of the experiment were completed. 
In part 2, participants were asked to provide a guess about the bid of the other paired participant in part 1. Participants were not aware of part 2 until after they finished part $1 .^{5}$ Participants received an additional $\$ 2$ if their guess was equal to the bid made by the other participant. The actual earnings for this part were determined at the end of the experiment.

In part 3, each participant was randomly and anonymously matched with another participant. The rules for part 3 were exactly the same as the rules for part 1 with an exception that the winner of the contest received a prize of $\$ 0$ (Sheremeta, 2010). Participants were told that they would be informed whether they won the contest or not and that all participants would have to pay their bids. This procedure was used to measure how important it is for participants to win when winning is costly and there is no monetary reward for winning the contest. The actual results for this part were determined at the end of the experiment.

In part 4, similar to Charness and Rabin (2002), participants made 12 binary choices measuring social preferences. The choices involved additional income for themselves and another participant with whom they were randomly and anonymously paired. Each choice offered the option of $\$ 3$ to both "self" and "other" or an unequal amount with total value between $\$ 3.50$ and $\$ 8.50$. One of the 12 choices was randomly selected to be paid out at the end of the experiment (and one of the paired participants was randomly selected as a decision maker, while the other was selected as a receiver).

In part 5, participants made two decisions similar to those described by Ellsberg (1961). Participants were told that the computer would randomly draw a ball from a virtual bag containing 30 red balls and 60 other balls that are either blue or green. The first decision was between option A ( $\$ 5$ if a red ball is drawn) and option B ( $\$ 5$ if a blue ball is drawn). The second

\footnotetext{
${ }^{5}$ We intentionally chose to elicit a belief about the bid of the other paired participant after eliciting the actual bidding strategy (but before revealing outcomes) in order to circumvent hedging issues that may arise when eliciting behavior and beliefs. It is documented, however, that hedging confounds are not problematic (Blanco et al., 2010).
} 
decision was between option A ( $\$ 5$ if a red or green ball is drawn) and option B ( $\$ 5$ if a blue or green ball is drawn). Participants also made two incentivized decisions similar to those described by Allais (1953). The decision was between option A (receiving $\$ 5$ for sure) and option B (89\% chance of receiving $\$ 5,1 \%$ chance of receiving nothing, and $10 \%$ chance of receiving $\$ 25)$. The next decision was between option A (89\% chance of receiving nothing, and $11 \%$ chance of receiving \$5) and option B (90\% chance of receiving nothing, and 10\% chance of receiving \$25). One of the 4 choices was randomly selected to be paid out at the end of the experiment. These tasks were used to elicit systematic violations of the expected utility theory, thus providing us with a measure of systematic biases that could be linked to overbidding.

In part 6, following Shupp et al. (2013), we simultaneously elicited participants' preferences toward risk and losses. In the first 15 decisions, participants were asked to choose between a risky option A ( $\$ 0$ or $\$ 5$ with $50 \%$ chance each) and a safe option B (increasing monotonically from $\$ 0.50$ to $\$ 4$ ). In the next 15 decisions, participants chose between a risky option A (50\% chance of receiving $\$ 5$ or losing a certain amount between $-\$ 0.50$ to $-\$ 7.50)$ and a safe option B of $\$ 0$. One of the 30 choices was randomly selected to be paid out at the end of the experiment. As in previous parts, participants were not aware of this part until after they finished the preceding part.

In part 7, participants completed a three-question Cognitive Reflection Test (CRT) measuring impulsivity of behavior (Frederick, 2005). The three questions involved making simple calculations and were designed to have an appealing but incorrect answer. For example, the first question was " $\mathrm{A}$ bat and a ball cost $\$ 1.10$ in total. The bat costs $\$ 1.00$ more than the ball. How much does the ball cost?” The appealing but incorrect answer is $\$ 0.10$. The correct answer 
is $\$ 0.05$. All three questions were incentivized, with participants receiving $\$ 0.50$ per each correct answer.

In part 8 , participants completed a 10-minute cognitive test consisting of 7 multiplechoice mathematical questions. The questions were drawn from a Graduate Record Examination (GRE) test preparation book (Seltzer, 2009). The test was used to elicit cognitive ability of participants. Participants received $\$ 0.50$ per each correct answer.

At the end of the experiment, participants filled out a demographic questionnaire. After computer displayed outcomes from all parts of the experiment and calculated individual earnings, participants received their payments in private and in cash.

\section{Results}

We begin with an overview of bidding behavior in our experiment. Then we discuss one by one how different theories and corresponding measures can explain the observed bidding behavior. Finally, we perform a joint analysis which allows us to examine the relative importance of each explanatory factor and provide a unified explanation for overbidding in rentseeking contests.

\subsection{Bidding Behavior in Contests}

Figure 1 displays the distribution of bids in our experiment. There are two noticeable deviations from the theoretical predictions. First, instead of a unique pure-strategy equilibrium of $\$ 2$, bids are distributed between $\$ 0$ and $\$ 10$. Second, $79.3 \%$ of bids are higher than the equilibrium, indicating significant overbidding (Wilcoxon signed-rank test, p-value $<0.01$ ). On average, participants bid $\$ 3.62$, which is $\$ 1.62$ higher than the equilibrium. As a result of 
overbidding, participants earn only $\$ 0.38$ on average, which is significantly less than the predicted $\$ 2$ (Wilcoxon signed-rank test, p-value < 0.01). Although these findings are consistent with dozens of other experimental studies reviewed by Dechenaux et al. (2015), they create a puzzle for economists: Why do so many participants choose dominated strategies to the detriment of their own earnings? The first explanation that we consider is mistakes.

\subsection{Overbidding and Mistakes}

In Section 2 we discussed that there are no asymmetric or mixed-strategy equilibria in the two-player lotter contest, and the symmetric pure-strategy equilibrium is unique. Therefore, variation in bids and systematic overbidding by participants cannot be explained by other equilibria.

Perhaps participants make mistakes when evaluating behavior of others. ${ }^{6}$ Given that the value of the prize is $\$ 8$, according to the best-response function (3) any bid higher than $\$ 2$ is strictly dominated. Therefore, if participants believe that others are not going to play the equilibrium, we should observe underbidding. However, this is clearly not what we find. Figure 2 displays a scatterplot of individual bids versus beliefs about the other participant's bid, as well as the best-response function. Note that instead of an inverse U-shaped best-response function, there is a positive and significant correlation between bids and beliefs (Spearman's correlation coefficient is 0.33 , p-value $<0.01$ ). Given the stated beliefs, $90.8 \%$ of bids are greater than the

\footnotetext{
${ }^{6}$ One way of modeling mistakes in contests is through a quantal response equilibrium suggested by McKelvey and Palfrey (1995). In such an equilibrium, an individual plays a mixed strategy in which the probability of playing a pure strategy is increasing in the expected payoff of that strategy, given that others are playing the equilibrium mixed strategy as well. The implications of the quantal response equilibrium to contests have been tested in the lab and found significant support in the data (Sheremeta, 2011; Chowdhury et al., 2014; Lim et al., 2014).
} 
best response. This suggests that overbidding cannot be simply explained by incorrect beliefs about the behavior of others. ${ }^{7}$

Another possibility is that participants simply do not understand the game in which they participate. Recall from Section 3 that after reading the instructions, but before making their decisions, participants completed an incentivized quiz to verify their understanding of the game. Participants answered five quiz questions testing their understanding of the rules of the game as well as the ability to calculate simple best responses (see Appendix A). We find that $89.9 \%$ of participants answered at least three questions correctly. Figure 3 displays the average bid and relative overbidding (i.e., the difference between the actual bid and the best-response calculated based on the stated belief about the other bid) by correct quiz answers. The average bid decreases as participants answer more quiz questions correctly (Spearman's correlation coefficient is -0.21 , p-value < 0.01). ${ }^{8}$ The same is true for the relative overbidding (Spearman's correlation coefficient is $-0.21, \mathrm{p}$-value $<0.01)$. Together, these findings suggest that participants who make more mistakes by answering fewer quiz questions are more likely to overbid in rent-seeking contests.

\subsection{Systematic Biases}

It is well documented in the behavioral economics literature that besides mistakes, people exhibit systematic biases (Camerer et al., 2011). According to the prospect theory of Kahneman and Tversky (1979), people have difficulties evaluating probabilities and they are loss averse,

\footnotetext{
${ }^{7}$ One may argue that participants use the belief question to diversify their risk since both the payoff from belief elicitation and the payoff from the contest depend on the same action of the opponent. However, such hedging is uncommon (Blanco et al., 2010). Moreover, there are no beliefs that a participant could hold that would make overbidding optimal.

${ }^{8}$ We have also tried to look at the average bid separately by each quiz question and found that participants who answer a given quiz question correctly on average bid less.
} 
placing higher weight on losses than gains. Given that contests involve both probabilistic outcomes and potential gains and loss, such biases could potentially explain observed behavior in rent-seeking contests. ${ }^{9}$

To examine how systematic biases impact behavior in contests, we asked participants to make two choices between option A and option B corresponding to the Ellsberg paradox (Ellsberg, 1961) and two choices corresponding to the Allais paradox (Allais, 1953), see Section 3 for details. In both paradoxes, choosing AA or BB is consistent with the expected utility theory. However, laboratory experiments have shown that participants often violate the expected utility theory by commonly choosing $\mathrm{AB}$ when facing the Ellsberg paradox (Camerer and Weber, 1992; Binmore et al., 2012) or the Allais paradox (Kahneman and Tversky, 1979; Conlisk, 1989; Starmer and Sugden, 1991). Similarly, we find that $73.9 \%$ of participants facing the Ellsberg paradox and $9.8 \%$ of participants facing the Allais paradox violate the expected utility theory in our experiment by choosing $\mathrm{AB} .{ }^{10}$

Next, we examine whether participants who violate the expected utility theory behave differently in rent-seeking contests. Figure 4 shows the average bid by systematic bias. Participants who do not display any bias on average bid $\$ 3.52$, which is similar to the bid of $\$ 3.60$ by participants who display one bias (either Ellsberg or Allais), and similar to the bid of $\$ 3.98$ by participants who display both biases. None of these pairwise comparisons are significant (Wilcoxon rank-sum test, all p-values > 0.61). Therefore, it appears that biases elicited through the Ellsberg and Allais paradoxes do not explain behavior in contests.

\footnotetext{
9 Studies show that when the contest success function is replaced by a share function, eliminating possible probability distortion and losses, behavior in contests is closer to the Nash equilibrium (e.g., Fallucchi et al., 2013; Shupp et al., 2013; Chowdhury et al., 2014).

10 The relatively low violation rate in the Allais paradox is likely due to small payoffs and real monetary payments (Huck and Müller, 2012).
} 
Perhaps the best documented bias suggested by the prospect theory is loss aversion (Kahneman, 2011). Given that contests involve potential gains and losses, loss aversion may be an important factor in explaining systematic deviations of individual behavior from the equilibrium (Eisenkopf and Teyssier, 2013; Shupp et al., 2013). To incorporate loss-aversion into a contest model assume that an individual places a weight $\lambda>1$ on losses and a weight 1 on gains. ${ }^{11}$ Thus, the payoff function (2) for individual $i$ can be rewritten as:

$$
\pi_{i}\left(b_{i}, b_{j}\right)=p_{i}\left(b_{i}, b_{j}\right)\left(v-b_{i}\right)+\left(1-p_{i}\left(b_{i}, b_{j}\right)\right) \lambda\left(-b_{i}\right) .
$$

Differentiating (5) and solving for the equilibrium gives the equilibrium bids:

$$
b_{i}^{\lambda}=b_{j}^{\lambda}=b^{\lambda}=v /(3+\lambda) \text {. }
$$

This analysis shows that the equilibrium bid decreases in the loss-aversion parameter $\lambda$. Similar calculations could be done to demonstrate that the equilibrium bid decreases in riskaversion (Hillman and Katz, 1984). To test these predictions, following Shupp et al. (2013), we simultaneously elicited participants' preferences toward risk and losses using 30 binary lottery choices (see Section 3 and Appendix A for details). Each choice offered a risky lottery A or a safe option B. Choices were structured in such a way that participants would first choose option A and then switch to option $\mathrm{B}$, with the switching pointing indicating the degree of aversion to risk and losses. Most participants had one switching point, and less than 3\% made inconsistent choices. Based on our sample, we find that $67.4 \%$ of participants are risk-averse and $95.7 \%$ are loss-averse. Figure 5 shows a weak and insignificant correlation between bids and risk-aversion (Spearman's correlation coefficient is $-0.04, \mathrm{p}$-value $=0.59$ ). On the other hand, there is a negative and significant correlation between bids and loss-aversion (Spearman's correlation coefficient is $-0.16, \mathrm{p}$-value $=0.02$ ), indicating that participants who are more loss-averse on

\footnotetext{
${ }^{11}$ An implicit assumption here is that both individuals have the same loss-aversion parameter $\lambda$. The model could be easily extended to the case of different loss-aversion parameters.
} 
average tend to make lower binds in the contest. It is important to emphasize, however, that even the most loss-averse participants on average bid more than $\$ 3$ (see Figure 5), which is still $50 \%$ higher than the Nash equilibrium prediction.

\subsection{The Utility of Winning}

The standard economic assumption is that participants care only about the monetary prize associated with winning the contest. However, participants also may care about winning itself. Following Sheremeta (2010), we elicited a non-monetary utility of winning by asking participants to bid in a contest with a prize of $\$ 0 .{ }^{12}$ Participants were told that they would be informed whether they won the contest or not and that all participants would have to pay their bids. This procedure was used to measure how important it is for participants to "win" when winning is costly and there is no monetary reward for winning the contest.

We find that $46.7 \%$ of participants make positive bids in the contest with a zero prize, indicating that participants derive a utility from winning apart from monetary incentives. Moreover, Figure 6 shows that there is a positive and significant correlation between bids for a prize of $\$ 0$ and bids for a prize of $\$ 8$ (Spearman's correlation coefficient is 0.31, p-value $<0.01$ ), suggesting that the utility of winning could be driving overbidding in contests. ${ }^{13}$ However, it is also possible that part of this correlation is due to the fact that participants who are confused when bidding for a prize of $\$ 0$ are also confused when bidding for a prize of $\$ 8$. Indeed, we find that the average bid for a prize of $\$ 0$ decreases as participants answer more quiz questions about

\footnotetext{
12 Other ways of measuring the utility of winning include using questionnaires (Altmann et al., 2012; Kräkel and Nieken, 2015) or content analysis (Sheremeta and Zhang, 2010; Cason et al., 2012, 2016).

${ }^{13}$ Similar to the utility of winning, Delgado et al. (2008) suggest that another explanation for overbidding is a disutility of losing. They provide evidence for the disutility of losing in the context of a first-price auction. Currently, there is no study examining the disutility of losing as an explanation for overbidding in contests. What is even a more interesting question is how to distinguish the utility of winning from the disutility of losing. These questions are definitely worth pursuing for future research.
} 
the contest game correctly (Spearman's correlation coefficient is -0.16 , p-value $=0.02$ ). Although the fact that the correlation is weak suggests that bidding for zero is measuring not only confusion but also the utility of winning. ${ }^{14}$

One could incorporate the utility of winning into the theoretical model presented in Section 2 by assuming that in addition to the prize value $v$, individuals also have an additive non-monetary utility of winning $w$. Therefore, the updated expected payoff of individual $i$ can be written as

$$
\pi_{i}^{w}\left(b_{i}, b_{j}\right)=p_{i}\left(b_{i}, b_{j}\right)\left(v+w-b_{i}\right)+\left(1-p_{i}\left(b_{i}, b_{j}\right)\right)\left(-b_{i}\right)
$$

In such a case, the new equilibrium bids derived from (7) are:

$$
b_{i}^{w}=b_{j}^{w}=b^{w}=(v+w) / 4
$$

Note that the equilibrium bid (8) increases in the non-monetary utility of winning $w$, and for any $w>0$, it is higher than the standard equilibrium bid (4). Therefore, since we find evidence that for $46.7 \%$ of participants $w>0$, the non-monetary utility of winning could partially explain overbidding by these participants.

\subsection{Relative Payoff Maximization}

Several studies suggested that overbidding may be driven by relative payoff maximization (Herrmann and Orzen, 2008; Fonseca, 2009; Eisenkopf and Teyssier, 2013; Mago

et al., 2016). Many preference structures are consistent with relative payoff maximization. For example, it may be the case that individuals are spiteful (Hamilton, 1970), have social preferences (Fehr and Schmidt, 1999), or that they behave in a manner predicted by evolutionary

\footnotetext{
14 Indeed, when we estimate an OLS regression in which the dependent variable is a bid for a prize and the independent variables are a bid for zero and a number of correctly answered quiz questions, we find that both variables are significant in predicting bidding behavior. We perform a more general joint analysis of all explanatory factors in Section 4.7.
} 
game theory (Leininger, 2003; Hehenkamp et al., 2004). Irrespective of its origin, one could model relative payoff maximization into a contest by assuming that the expected utility of individual $i$ depends on the difference between an individual payoff $\pi_{i}\left(b_{i}, b_{j}\right)$ and the weighted payoff of the opponent $r \pi_{j}\left(b_{i}, b_{j}\right):^{15}$

$$
u_{i}\left(b_{i}, b_{j}\right)=\pi_{i}\left(b_{i}, b_{j}\right)-r \pi_{j}\left(b_{i}, b_{j}\right)
$$

where $r$ is a relative payoff parameter, with $r<0$ reflecting preferences of a prosocial individual seeking to increase the payoff of the opponent, and $r>0$ reflecting preferences of a competitive individual seeking to obtain a higher relative payoff than the opponent.

Differentiating (9) with respect to $b_{i}$ (similarly $b_{j}$ ) and solving for the equilibrium gives the equilibrium bids:

$$
b_{i}^{r}=b_{j}^{r}=b^{r}=(1+r) v / 4 .
$$

This analysis shows that competitive individuals (i.e., $r>0$ ) should bid more than prosocial individuals (i.e., $r<0$ ). To test this prediction, following Charness and Rabin (2002), we elicited social preferences using 12 binary choices as shown in Table 2. Each choice offered an option $\mathrm{A}$ of $\$ 3$ to both self and other or an option B of unequal amount. We use these choices to distinguish participants who always maximize social welfare from those who are competitive.

Note that choosing B over A in 1-6 implies that a participant is competitive, since such a participant chooses to sacrifice social welfare to have a higher payoff than the opponent. Interestingly, participants who choose $\mathrm{B}$ in 1-6, indicating competitive behavior, make significantly higher bids in the contest than participants who choose A (see columns five and six

\footnotetext{
15 The utility function (9) is most commonly used in evolutionary contest theory (Leininger, 2003; Hehenkamp et al., 2004). The idea is that the objective of a contestant is not necessarily to maximize the expected payoff, but to "survive" by outperforming the rival.
} 
in Table 2) ${ }^{16}$ Similarly, we find that participants who choose A in 7-12, indicating competitive behavior, make significantly higher bids in the contest than participants who chose $\mathrm{B}$.

Next, we create a measure of competitive social preferences as the number of choices in which a participant chooses to sacrifice social welfare to be ahead the other participant (i.e., choosing B over A in 1-6) or not to be behind the other participant (i.e., choosing A over B in 712). Using this measure, we find that there is a positive and significant correlation between competitiveness and bidding (Spearman's correlation coefficient is 0.19 , p-value $<0.01$ ). Similarly, we find a positive and significant correlation between competitiveness and relative overbidding (Spearman's correlation coefficient is 0.17 , p-value $=0.02$ ). Together, these findings suggest that competitiveness may be driving overbidding in rent-seeking contests, and that overbidding is a competitive phenomenon.

\subsection{Impulsive Behavior and Cognitive Ability}

Dual-system theories of cognitive decision-making suggest that people make their decisions using "System 1" or "System 2". Kahneman (2011) describes System 1 as impulsive and effortless, while System 2 as reflective and calculative (resembling a standard economic thinking). The predictions of the theoretical model described in Section 2 rest on the assumptions that individuals use System 2 when bidding in rent-seeking contests. However, as Kahneman points out, most choices are usually made by System 1 . Therefore, we should not be surprised by systematic deviations of behavior from the theoretical predictions.

There are several methods to test the implications of the dual-system theory by isolating impulsive and reflective cognitive processes. For the purpose of our study, we chose to assess participants' impulsivity using a Cognitive Reflection Test (CRT), which measures the ability to

\footnotetext{
${ }^{16}$ There are very few participants choosing B in choices 4-6, so the differences are not significant.
} 
override impulsive responses and to engage in further reflection before making a decision (Frederick, 2005). ${ }^{17}$ Specifically, participants completed three math questions (see Section 3 and Appendix A for details). The simple math questions were easily solvable, yet had intuitively compelling incorrect answers. To reach the correct answer, the participant had to engage reflective System 2 in order to override the impulsive response of System $1 .^{18}$

We find that only $16.8 \%$ of participants were able to answer all three CRT questions correctly, while $33.1 \%$ answered all three questions incorrectly. The top histogram in Figure 7 shows the average bid by CRT. It is apparent that the average bid decreases as participants answer more CRT questions correctly (Spearman's correlation coefficient is -0.33 , p-value < 0.01). Moreover, participants who answer all three CRT questions correctly on average bid $\$ 2.56$, which is relatively close to the equilibrium prediction of $\$ 2$. On the other hand, participants who answer all three CRT questions incorrectly on average bid $\$ 4.38$. Given the observed empirical distribution of bids in the rent-seeking contest, the expected payoff of the most reflective participants is $\$ 0.77$, while the expected payoff of the most impulsive participants is only $\$ 0.07$. Therefore, it appears that more reflective and less impulsive participants overbid less and earn higher expected payoffs in rent-seeking contests.

One could argue that the CRT simply captures the cognitive ability of participants to solve math problems, and participants who have higher cognitive ability in general are better at

\footnotetext{
${ }^{17}$ Using the CRT to study impulsive and reflective behavior is a trait-based approach which relies on the assumption that individuals with an impulsive cognitive style are more likely to make decisions guided by System 1, whereas reflective individuals are more likely to be driven by System 2 (Oechssler et al., 2009; Corgnet et al., 2015; Peysakhovich and Rand, 2016). Other methods used by behavioral researchers rely on the analysis of reaction time (e.g., Rubinstein, 2007, 2013; Piovesan and Wengström, 2009; Rand et al., 2012), and the use of experimental manipulations, such as cognitive load (e.g., Cornelissen et al., 2011; Benjamin et al., 2013; Duffy and Smith, 2014; Deck and Jahedi, 2015) or time pressure (e.g., Rand and Kraft-Todd, 2014; Rand et al., 2015).

18 The responses to the CRT are indeed a good proxy for the individuals' tendency to make impulsive versus reflective decisions. The CRT has been found to correlate with one's ability to delay gratification (Frederick, 2005) and to predict one's ability to refrain from using inaccurate heuristics in a variety of situations (Oechssler et al., 2009, Toplak et al., 2011).
} 
figuring out the equilibrium play in other games (Gill and Prowse, 2016). To test this hypothesis, we elicited a different measure of participants' cognitive ability to solve math problems. Specifically, participants completed a 10-minute cognitive test consisting of 7 multiple-choice mathematical questions drawn from a GRE test preparation book (Seltzer, 2009). The bottom histogram in Figure 7 shows the average bid by GRE. Although there is a negative correlation between the average bid and the number of correct GRE answers, the trend is somewhat weaker and less significant (Spearman's correlation coefficient is -0.14 , $\mathrm{p}$-value $=0.05$ ).

To summarize, both CRT and GRE predict bidding behavior in contests. Moreover, there is a positive and significant correlation between the number of correct CRT and GRE answers (Spearman's correlation coefficient is 0.34 , p-value $<0.01$ ), which is not surprising since cognitive abilities are required to answer both tests. The fact that the correlation is moderate suggests that the CRT and the GRE are measuring somewhat different cognitive skills (Stanovich, 2009). While the GRE measures participants' cognitive ability to solve math problems, the CRT measures the tendency to resist the impulsive behavior and reflect on the task. In order to examine whether cognitive ability or impulsivity is more important in explaining behavior in rent-seeking contests, we employ a multivariate analysis.

\subsection{Joint Analysis of Measured Behaviors}

Table 3 shows the correlation matrix of our measured behaviors, with colored cells indicating statistically significant correlations. Consistent with our previous observations, bid is significantly correlated with belief (belief about the other bid), quiz (number of correct quiz answers), loss-averse (number of options B), bid-zero (bid for a prize of \$0), competitive (number of antisocial competitive choices), gre (number of correct GRE answers), and crt 
(number of correct CRT answers). However, it is clear from Table 3, that some of these variables are also correlated with each other. For example, loss-averse is correlated with bias (number of decisions violating the expected utility) and risk-averse (number of safe options $\mathrm{B}$ ), which is expected since all three measures are designed to capture systematic biases.

The variable that has the strongest correlation with other variables, besides bid, is crt. Previously we discussed that besides impulsivity, the CRT is measuring cognitive ability, and thus it is not surprising that crt is positively correlated with gre. For the same reason, it is not surprising that crt is positively correlated with quiz, since both tasks require cognitive ability. Surprisingly, however, crt is negatively and significantly correlated with competitive, suggesting that more impulsive participants (i.e., participants who score less on the CRT) are more competitive (i.e., participants who choose to sacrifice social welfare to be ahead or not to be behind of others). ${ }^{19}$ Given that $c r t$ is correlated with both competitive and bid, it is possible that the correlation between competitive and bid is mainly driven by crt. Of course, the reverse could be true as well. Therefore, we employ a multivariate analysis.

Table 4 shows the estimation results of different OLS regressions in which the dependent variable is bid, and the independent variables are measured behaviors reported in Table 3. Specification (1) supports the findings from Section 4.2, by showing that bid is positively correlated with belief and negatively correlated with quiz. Specification (2) supports the findings from Section 4.3, by showing that out of different measures of systematic biases only loss-averse is significantly correlated with bid. Similarly, specifications (3) and (4) support the findings from Sections 4.4 and 4.5, by showing that bid is positively correlated with bid-zero and competitive. Recall from Section 4.6 that bid, gre, and crt are all correlated (this can also be seen in Table 3).

\footnotetext{
19 This result is also robust when we consider alternative definitions of competitiveness (see Table B1 and the corresponding discussion in Appendix B).
} 
Specification (5), however, shows that when we include both gre and crt as explanatory variables, only $c r t$ is significant. Therefore, we conclude that it is mainly impulsivity, and not cognitive ability to do mathematical computations, that influences behavior in rent-seeking contests.

To further explore the joint effect of all measured behaviors on bidding behavior we estimate specification (6), in which we include all of the explanatory variables. Interestingly, most of the variables, including quiz, loss-averse, bid-zero, and competitive, that previously were significant in specifications (1) through (4) become insignificant. The only variables that remain significant are belief and crt. To see which of these two variables captures most of the explanatory power from other variables, we re-estimate all specifications in Table 4 controlling separately for belief and crt. When we control for belief, as shown in Table 5, all of the results reported in specifications (2) through (5) in Table 4 are virtually unchanged. On the other hand, when we control for $c r t$, as shown in Table 6, most of the explanatory variables, including quiz, loss-averse, bid-zero, and competitive, become insignificant. Therefore, it appears that crt captures most of the explanatory variance for bidding behavior in the rent-seeking contest. On average, one correctly answered CRT question reduces the bid by $\$ 0.43-\$ 0.58$, depending on the exact regression in Table 6 . This translates into a gap of $\$ 1.29-\$ 1.74$ between the most impulsive participants (who answer zero CRT questions correctly) and the most reflective participants (who answer all three CRT questions correctly). ${ }^{20}$

We have also checked the robustness of these results, by using overbidding (i.e., the difference between the actual bid and the best-response calculated based on the stated belief about the other bid), instead of bid, as a dependent variable. The results reported in Table B2 in Appendix B are very similar qualitatively to those reported in Table 4. Also, we used expected

\footnotetext{
${ }^{20}$ Recall that the equilibrium bid is $\$ 2$.
} 
payoff (i.e., the average expected payoff calculated based on the individual bid and the empirical distribution of all other bids in our sample) as a dependent variable. Again, the results reported in Table B3 in Appendix B are very similar qualitatively.

Combined, these estimation results tell a consistent story. Specifications (1) through (5) in Table 4 provide evidence that overbidding in contests is correlated with mistakes (specification 1), systematic biases (specification 2), the utility of winning (specification 3), relative payoff maximization (specification 4), and impulsive behavior (specification 5). However, when putting together in a joint multivariate analysis (specification 6), only impulsivity remains significant, suggesting that overbidding is primarily driven by impulsive behavior. Estimations reported in Table 6 further confirm that impulsivity is correlated with other explanatory factors and thus it is the main moderating factor which explains overbidding in rent-seeking contests.

\section{Discussions and Conclusion}

In this paper we have examined the predictive power of different theories to explain overbidding in rent-seeking contests. For this purpose, we conduct an eight-part experiment. Our results showed significant support for the existing theories of overbidding, such as mistakes, systematic biases, the utility of winning, and relative payoff maximization. Besides the existing theories of overbidding, we discovered some new explanations, such as cognitive ability and impulsive behavior. Out of all explanations examined, we found that impulsive behavior, measured through a Cognitive Reflection Test, is the most important factor explaining the overbidding phenomenon. 
Our results not only provide an explanation for a long standing puzzle about overbidding in rent-seeking contests, but also explain why some studies find less overbidding than others. Fallucchi et al. (2013) and Chowdhury et al. (2014), for example, show that there is less overbidding when the rules of the contest are simplified and when participants receive more feedback. Similarly, Sheremeta and Zhang (2010) find that overbidding is reduced when, instead of individuals, groups of two participants make decisions in contests. These manipulations reduce cognitive load, allowing participants to make more deliberate and less impulsive choices. Given that impulsivity is the main factor driving overbidding in contests, it is not surprising that studies that reduce cognitive load of participants find less overbidding.

Besides explaining previous experimental findings from the contest literature, our results have important implications for social science in general. Specifically, our findings indicate that participants with more competitive preferences (e.g., participants who choose to sacrifice social welfare to be ahead of others) are more impulsive. Furthermore, our findings also indicate that bidding behavior in rent-seeking contests is a competitive phenomenon which is driven by impulsive behavior. An important implication of this is that individuals who are better at controlling their impulsive behavior (i.e., using System 2 instead of System 1), should be less likely to engage in irrational competitions. ${ }^{21}$ This interpretation is also consistent with research examining evolution of prosocial behavior of children (Bloom, 2013; Fehr et al., 2008, 2013). The main conclusion from this literature is that children (who one could argue are mostly guided by System 1) display very competitive and spiteful behavior in their early years of life; however,

\footnotetext{
${ }^{21}$ This result contrasts the "social heuristics hypothesis," claiming that cooperative behavior is more intuitive (Rand et al., 2014). In fact, we find exactly the opposite: Individuals who are more impulsive (i.e., use intuitive System 1) are more competitive and bid more aggressively in contests than individuals who are more reflective (i.e., use System 2). Therefore, our results align with the literature suggesting that cooperative behavior is not impulsive (Piovesan and Wengström, 2009; Tinghog et al., 2013; Verkoeijen and Bouwmeester, 2014).
} 
as they grow older (and thus become more capable of using System 2) they display more cooperative behavior.

Our results also have implications for economic theory. The standard economic theory is based on the assumption that economic agents are perfectly rational and they do not make mistakes. However, as research suggests, this is not necessarily the case (Camerer, 2003). ${ }^{22}$ Kahneman (2011) argues that one reason why individuals make "irrational" choices is that they often ignore the reflective System 2 (which is needed to make rational economic decisions) and instead use the impulsive System 1 (which is inclined to biases and errors). ${ }^{23}$ An important implication of this is that if one could get a good indication whether an individual is indeed using System 2 in economic decision-making, then one could reliably test the economic theory. We find that the CRT is such an indicator. In our experiment, the most impulsive participants who answer all three CRT questions incorrectly on average bid $\$ 4.38$ (which is $119 \%$ higher than the theoretical prediction), while the most reflective participants who answer all three questions correctly bid $\$ 2.56$ (which is only $28 \%$ away from the theoretical prediction). Thus, we can conclude that the behavior of participants who score higher on the CRT, indicating better use of System 2, is more in line with the economic theory; and researchers who want to test other theoretical models of rent-seeking should use this information to make their conclusions about the predictive power of the theory.

There are, of course, a number of avenues for future research. First, one could use other methods to examine the implications of the dual-system theory for overbidding. For example, one could use the reaction time (e.g., Rubinstein, 2007, 2013) to examine the impact of

\footnotetext{
${ }^{22}$ Cason and Plott (2014), for example, show that even in the simplest laboratory experiments individuals routinely make mistakes which cannot be explained neither by standard nor by nonstandard preference theories.

${ }^{23}$ Rubinstein (2016) suggest a new typology of players based on the classification of actions as either instinctive (impulsive) or contemplative (reflective).
} 
impulsivity on behavior in rent-seeking contests. Unfortunately, due to the nature of our experiment, we could not use the reaction time as a measure of impulsivity. Reading the instructions in each experimental session took much time, giving participants plenty of opportunity to think over their decisions even before they could actually input their decision into the computer. One could also use experimental manipulations, such as cognitive load (e.g., Cornelissen et al., 2011; Benjamin et al., 2013; Duffy and Smith, 2014; Deck and Jahedi, 2015) or time pressure (e.g., Rand and Kraft-Todd, 2014; Rand et al., 2015), to directly examine how impulsivity drives overbidding in rent-seeking contests.

Finally, we conjecture that our findings potentially could be applied to explain overbidding in winner-pay auctions. There is a long standing debate about what could explain overbidding in first-price and common value auctions. Some of the explanations are similar to the ones that have been proposed to explain overbidding in rent-seeking contests. For example, Cox et al. (1992) suggest that part of the overbidding in auctions is caused by the joy of winning. Goeree et al. (2002) and Crawford and Iriberri (2007) suggest that overbidding is due to mistakes. Risk aversion and systematic biases have also been cited as possible explanations for overbidding in winner-pay auctions (Cox et al., 1988; Goeree et al., 2002). However, even after heated discussions by Cox et al. (1992), Friedman (1992), Kagel and Roth (1992), and Merlo and Schotter (1992), which followed Harrison's (1989) critique of Cox et al. (1982), the debate has not been resolved. We hypothesize that impulsivity, measured through a Cognitive Reflection Test, potentially could explain overbidding in winner-pay auctions. 


\section{References}

Abbink, K., Brandts, J., Herrmann, B., \& Orzen, H. (2010). Intergroup conflict and intra-group punishment in an experimental contest game. American Economic Review, 100, 420-447.

Allais, M. (1953). Le comportement de l'homme rationnel devant le risqué: Critique des postulats et axioms de l'ecole americaine. Econometrica, 21, 503-546.

Altmann, S., Falk, A., \& Wibral, M. (2012). Promotions and incentives: The case of multi-stage elimination tournaments. Journal of Labor Economics, 30, 149-174.

Arrow, K. J. (1974). General economic equilibrium: purpose, analytic techniques, collective choice. American Economic Review, 64, 253-272.

Benjamin, D.J., Brown, S.A., \& Shapiro, J.M. (2013). Who is 'behavioral'? Cognitive ability and anomalous preferences. Journal of the European Economic Association, 11, 1231-1255.

Binmore, K., Stewart, L., \& Voorhoeve, A. (2012). How much ambiguity aversion? Finding indifferences between Ellsberg's risky and ambiguous bets. Journal of Risk and Uncertainty, 45, 215-238.

Blanco, M., Engelmann, D., Koch, A., \& Normann, H.T. (2010). Belief elicitation in experiments: is there a hedging problem? Experimental Economics, 3, 412-438.

Bloom, P. (2013) Just babies: The origins of good and evil. New York: Crown

Camerer, C. (2003). Behavioral game theory. Princeton, NJ: Princeton University Press.

Camerer, C., \& Weber, M. (1992). Recent developments in measuring preferences: Uncertainty and ambiguity. Journal of Risk and Uncertainty, 5, 325-370.

Camerer, C.F., Loewenstein, G., \& Rabin, M. (2011). Advances in behavioral economics. Princeton, NJ: Princeton University Press.

Cason, T.N., \& Plott, C.R. (2014). Misconceptions and game form recognition: Challenges to theories of revealed preference and framing. Journal of Political Economy, 122, 1235-1270.

Cason, T.N., Sheremeta, R.M. \& Zhang, J. (2012). Communication and efficiency in competitive coordination games. Games and Economic Behavior, 76, 26-43.

Cason, T.N., Sheremeta, R.M. \& Zhang, J. (2016). Asymmetric and endogenous communication in competition between groups. Working Paper.

Charness, G., \& Rabin, M. (2002). Understanding social preferences with simple tests. Quarterly Journal of Economics, 117, 817-869.

Chowdhury, S.M., Sheremeta, R.M., \& Turocy, T.L. (2014). Overbidding and overspreading in rent-seeking experiments: Cost structure and prize allocation rules. Games and Economic Behavior, 87, 224-238.

Conlisk, J. (1989). Three variants on the Allais example. American Economic Review, 79, 392407.

Cook, T.D., Campbell, D.T., \& Day, A. (1979). Quasi-experimentation: Design \& analysis issues for field settings. Boston, MA: Houghton Mifflin.

Corgnet, B., Espín, A.M., \& Hernán-González, R. (2015). The cognitive basis of social behavior: Cognitive reflection overrides antisocial but not always prosocial motives. Frontiers in Behavioral Neuroscience, 9(287), 1-17.

Cornelissen, G., Dewitte, S., \& Warlop, L. (2011). Are social value orientations expressed automatically? Decision making in the dictator game. Personality and Social Psychology Bulletin, 37, 1080-1090. 
Cox, J.C., Roberson, B., \& Smith, V.L. (1982). Theory and behavior of single price auctions. In V. L. Smith, (Ed.), Research in Experimental Economics, Vol. 2, Greenwich, Connecticut: JAI Press, 1-43.

Cox, J.C., Smith, V.L., \& Walker, J.M. (1988). Theory and individual behavior of first-price auctions. Journal of Risk and Uncertainty, 1, 61-99.

Cox, J.C., Smith, V.L., \& Walker, J.M. (1992). Theory and misbehavior of first-price auctions: Comment. American Economic Review, 82, 1392-1412.

Crawford, V.P., \& Iriberri, N. (2007). Level-k auctions: Can a nonequilibrium model of strategic thinking explain the winner's curse and overbidding in private-value auctions? Econometrica, 75, 1721-1770.

Dechenaux, E., Kovenock, D., \& Sheremeta, R. M. (2015). A survey of experimental research on contests, all-pay auctions and tournaments. Experimental Economics, 18, 609-669.

Deck, C., \& Jahedi, S. (2015). The effect of cognitive load on economic decision making: A survey and new experiments. European Economic Review, 78, 97-119.

Del Rosal, I. (2011). The empirical measurement of rent-seeking costs. Journal of Economic Surveys, 25, 298-325.

Delgado, M.R., Schotter, A., Ozbay, E.Y., \& Phelps, E.A. (2008). Understanding overbidding: Using the neural circuitry of reward to design economic auctions. Science, 321, 1849-1852.

Duffy, S., \& Smith, J. (2014). Cognitive load in the multi-player prisoner's dilemma game: Are there brains in games? Journal of Behavioral and Experimental Economics, 51, 47-56.

Eisenkopf, G., \& Teyssier, S. (2013). Envy and loss aversion in tournaments. Journal of Economic Psychology, 34, 240-255.

Ellsberg, D. (1961). Risk, ambiguity and the Savage axioms. Quarterly Journal of Economics, 75, 643-669.

Fallucchi, F., Renner, E., \& Sefton, M. (2013). Information feedback and contest structure in rent-seeking games. European Economic Review, 64, 223-240.

Fama, E.F. (1970). Efficient capital markets: A review of theory and empirical work. Journal of Finance, 25, 383-417.

Fehr, E., \& Schmidt, K.M. (1999). A theory of fairness, competition, and cooperation. Quarterly Journal of Economics, 114, 817-868.

Fehr, E., Bernhard, H., \& Rockenbach, B. (2008). Egalitarianism in young children. Nature, 454, 1079-1083.

Fehr, E., Glätzle-Rützler, D., \& Sutter, M. (2013). The development of egalitarianism, altruism, spite and parochialism in childhood and adolescence. European Economic Review, 64, 369383.

Fischbacher, U. (2007). z-Tree: Zurich toolbox for ready-made economic experiments. Experimental Economics, 10, 171-178.

Fonseca, M.A. (2009). An experimental investigation of asymmetric contests. International Journal of Industrial Organization, 27, 582-591.

Frederick, S. (2005). Cognitive reflection and decision making. Journal of Economic Perspectives, 19, 25-42.

Friedman, D. (1992). Theory and misbehavior of first-price auctions: Comment. American Economic Review, 82, 1374-1378.

Garfinkel, M.R. \& Skaperdas, S. (2012). The Oxford Handbook of the Economics of Peace and Conflict. Oxford University Press, New York. 
Gill, D., \& Prowse, V.L. (2016). Cognitive ability, character skills, and learning to play equilibrium: A level-k analysis. Journal of Political Economy, forthcoming.

Goeree, J.K., Holt, C.A., \& Palfrey, T.R. (2002). Quantal response equilibrium and overbidding in private-value auctions. Journal of Economic Theory, 104, 247-272.

Hamilton, W.D. (1970). Selfish and spiteful behaviour in an evolutionary model. Nature, 228, 1218-1220.

Harrison, G.W. (1989). Theory and misbehavior of first-price auctions. American Economic Review, 79, 749-762.

Hehenkamp, B., Leininger, W., \& Possajennikov, A. (2004). Evolutionary equilibrium in Tullock contests: Spite and overdissipation. European Journal of Political Economy, 20, 1045-1057.

Herrmann, B., \& Orzen, H. (2008). The appearance of homo rivalis: Social preferences and the nature of rent seeking. University of Nottingham, Working Paper.

Hillman, A.L., \& Katz, E. (1984). Risk-averse rent seekers and the social cost of monopoly power. Economic Journal, 94, 104-110.

Huck, S., \& Müller, W. (2012). Allais for all: Revisiting the paradox in a large representative sample. Journal of Risk and Uncertainty, 44, 261-293.

Kagel, J.H., \& Roth, A.E. (1992). Theory and misbehavior in first-price auctions: Comment. American Economic Review, 82, 1379-1391.

Kahneman, D. (2011). Thinking, fast and slow. New York, NY: Farrar, Straus and Giroux.

Kahneman, D., \& Tversky, A. (1979). Prospect theory: An analysis of decision under risk. Econometrica, 47, 263-291.

Konrad, K.A. (2009). Strategy and Dynamics in Contests, New York, NY: Oxford University Press.

Kräkel, M., \& Nieken, P. (2015). Relative performance pay in the shadow of crisis. European Economic Review, 74, 244-268.

Krueger, A.O. (1974). The political economy of the rent-seeking society. American Economic Review, 64, 291-303.

Laband, D.N., \& Sophocleus, J.P. (1992). An estimate of resource expenditures on transfer activity in the United States. Quarterly Journal of Economics, 107, 959-983.

Lacomba, J.A., Lagos, F., Reuben, E., \& Van Winden, F. (2014). On the escalation and deescalation of conflict. Games and Economic Behavior, 86, 40-57.

Leininger, W. (2003). On evolutionarily stable behavior in contests. Economics of Governance, 4, 177-186.

Lim, W., Matros, A., \& Turocy, T. L. (2014). Bounded rationality and group size in Tullock contests: Experimental evidence. Journal of Economic Behavior and Organization, 99, 155167.

Mago, S.D., Savikhin, A.C. \& Sheremeta, R.M. (2016). Facing your opponents: Social identification and information feedback in contests. Journal of Conflict Resolution, 60, 459481.

Mauro, P. (1995). Corruption and growth. Quarterly Journal of Economics, 110, 681-712.

Merlo, A., \& Schotter, A. (1992). Theory and misbehavior of first-price auctions: Comment. American Economic Review, 82, 1413-1425.

Oechssler, J., Roider, A., \& Schmitz, P.W. (2009). Cognitive abilities and behavioral biases. Journal of Economic Behavior and Organization, 72, 147-152. 
Peysakhovich, A., \& Rand, D.G. (2016). Habits of virtue: Creating norms of cooperation and defection in the laboratory. Management Science, 62, 631-647.

Piovesan, M., \& Wengström, E. (2009). Fast or fair? A study of response times. Economics Letters, 105, 193-196.

Posner, R.A. (1975). The social cost of monopoly and regulation. Journal of Political Economy, $83,807-827$.

Price, C.R., \& Sheremeta, R.M. (2011). Endowment effects in contests. Economics Letters, 111, 217-219.

Price, C.R., \& Sheremeta, R.M. (2015). Endowment origin, demographic effects and individual preferences in contests. Journal of Economics and Management Strategy, 24, 597-619.

Rand, D.G., \& Kraft-Todd, G.T. (2014). Reflection does not undermine self-interested prosociality. Frontiers in Behavioral Neuroscience, 8(300), 1-8.

Rand, D.G., Greene, J.D., \& Nowak, M.A. (2012). Spontaneous giving and calculated greed. Nature, 489, 427-430.

Rand, D.G., Newman, G.E., \& Wurzbacher, O.M. (2015). Social context and the dynamics of cooperative choice. Journal of Behavioral Decision Making, 28, 159-166.

Rand, D.G., Peysakhovich, A., Kraft-Todd, G.T., Newman, G.E., Wurzbacher, O., Nowak, M.A., \& Greene, J.D. (2014). Social heuristics shape intuitive cooperation. Nature Communications, 3677, 1-12.

Rubinstein, A. (2007). Instinctive and cognitive reasoning: A study of response times. Economic Journal, 117, 1243-1259.

Rubinstein, A. (2013). Response time and decision making: An experimental study. Judgment and Decision Making, 8, 540-551.

Rubinstein, A. (2016). A typology of players: Between instinctive and contemplative. Quarterly Journal of Economics, 131, 859-890.

Schumpeter, J.A. (1942). Socialism, capitalism and democracy. New York: Harper and Brothers

Seltzer, N. (2009). GRE practice questions. Princeton Review.

Sheremeta, R.M. (2010). Experimental comparison of multi-stage and one-stage contests. Games and Economic Behavior, 68, 731-747.

Sheremeta, R.M. (2011). Contest design: An experimental investigation. Economic Inquiry, 49, 573-590.

Sheremeta, R.M. (2013). Overbidding and heterogeneous behavior in contest experiments. Journal of Economic Surveys, 27, 491-514.

Sheremeta, R.M. (2015). Behavioral dimensions of contests. In Congleton, R.D., Hillman, A.L., (Eds.), Companion to political economy of rent seeking, London: Edward Elgar, pp. 150-164.

Sheremeta, R.M., \& Zhang, J. (2010). Can groups solve the problem of over-bidding in contests? Social Choice and Welfare, 35, 175-197.

Shupp, R., Sheremeta, R.M., Schmidt, D., \& Walker, J. (2013). Resource allocation contests: Experimental evidence. Journal of Economic Psychology, 39, 257-267.

Smith, V.L. (1962). An experimental study of competitive market behavior. Journal of Political Economy, 70, 111-137.

Stanovich, K.E. (2009). What intelligence tests miss: The psychology of rational thought. Yale University Press.

Starmer, C., \& Sugden, R. (1991). Does the random-lottery incentive system elicit true preferences? An experimental investigation. American Economic Review, 81, 971-978. 
Szidarovszky, F., \& Okuguchi, K. (1997). On the existence and uniqueness of pure Nash equilibrium in rent-Seeking games. Games and Economic Behavior, 18, 135-140.

Terwiesch, C., \& Xu, Y. (2008). Innovation contests, open innovation, and multiagent problem solving. Management Science, 54, 1529-1543.

Tinghög, G., Andersson, D., Bonn, C., Böttiger, H., Josephson, C., Lundgren, G., et al. (2013). Intuition and cooperation reconsidered. Nature, 498, 1-3.

Toplak, M.E., West, R.F., \& Stanovich, K.E. (2011). The Cognitive Reflection Test as a predictor of performance on heuristics-and-biases tasks. Memory and Cognition, 39, 12751289.

Tullock, G. (1980). Efficient rent seeking. In James M. Buchanan, Robert D. Tollison, Gordon Tullock, (Eds.), Toward a theory of the rent-seeking society. College Station, TX: Texas A\&M University Press, pp. 97-112.

Verkoeijen, P.P., \& Bouwmeester, S. (2014). Does intuition cause cooperation? PloS One, 9(5), $1-8$. 
Figure 1: Distribution of bids.

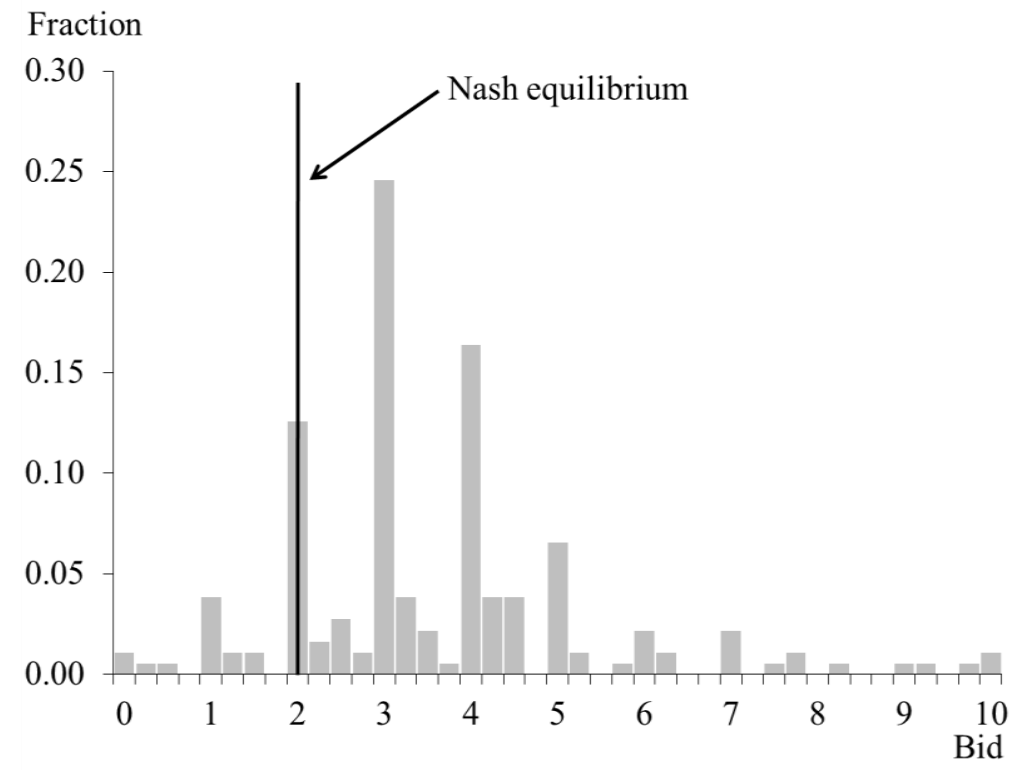


Figure 2: Bids, beliefs and best-responses.

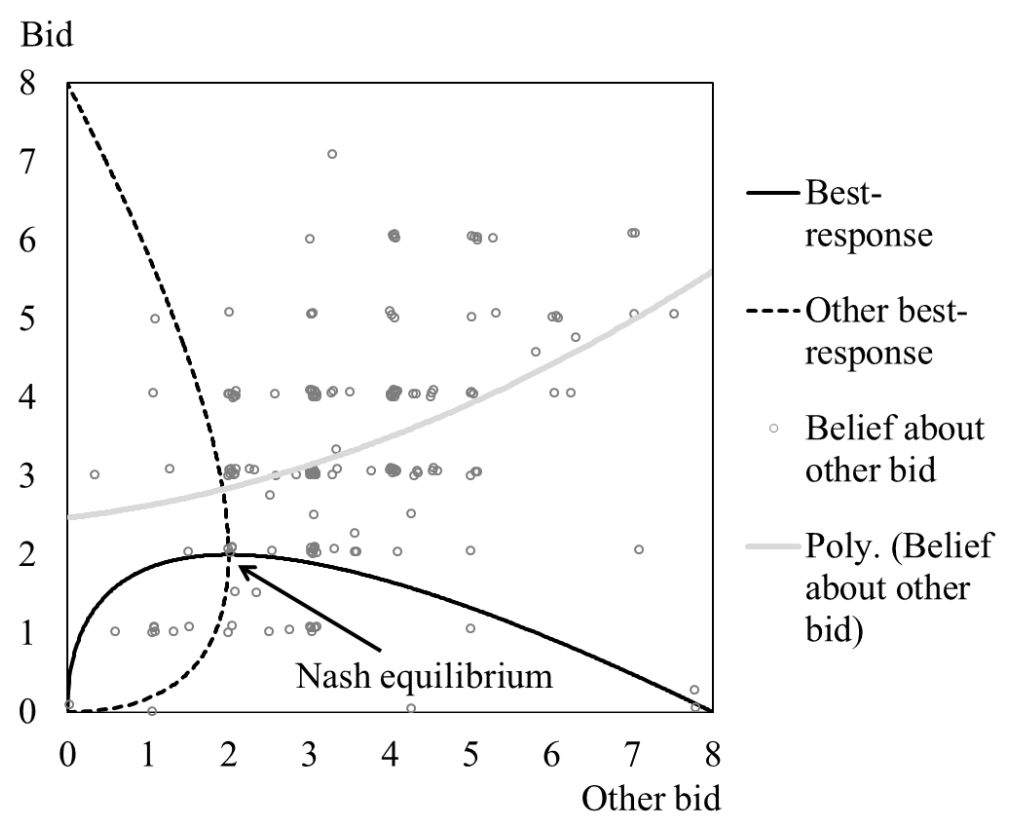


Figure 3: Average bid and relative overbidding by correct quiz answers.
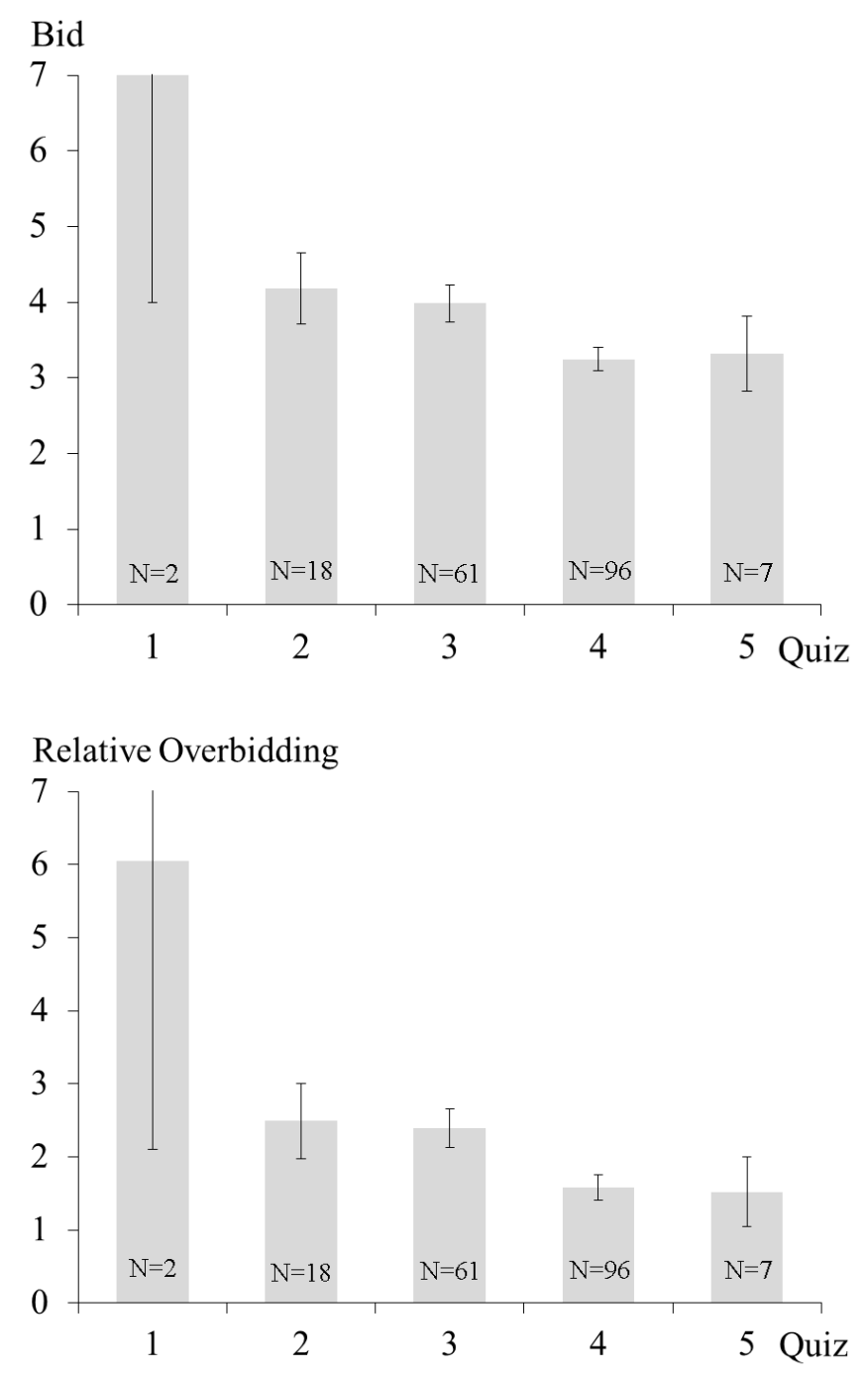
Figure 4: Average bid by systematic bias.

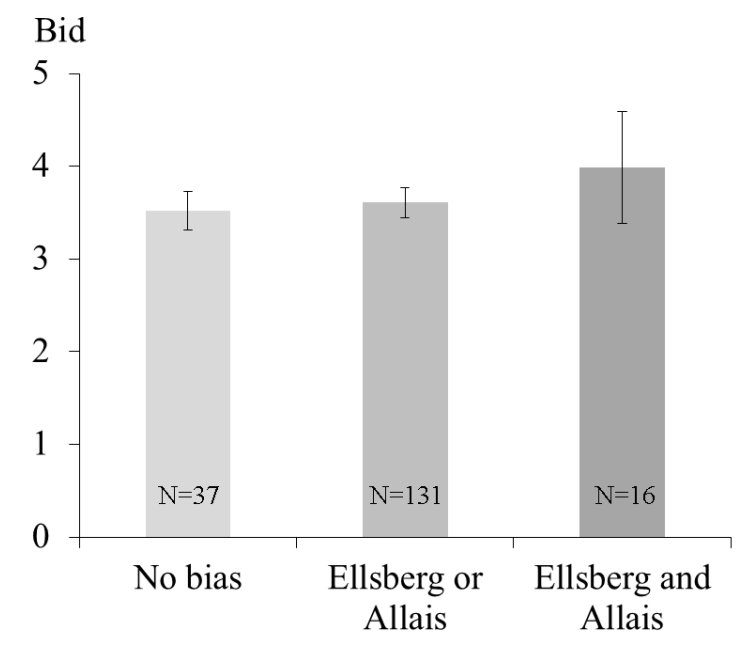


Figure 5: Average bid versus risk-aversion and loss-aversion.
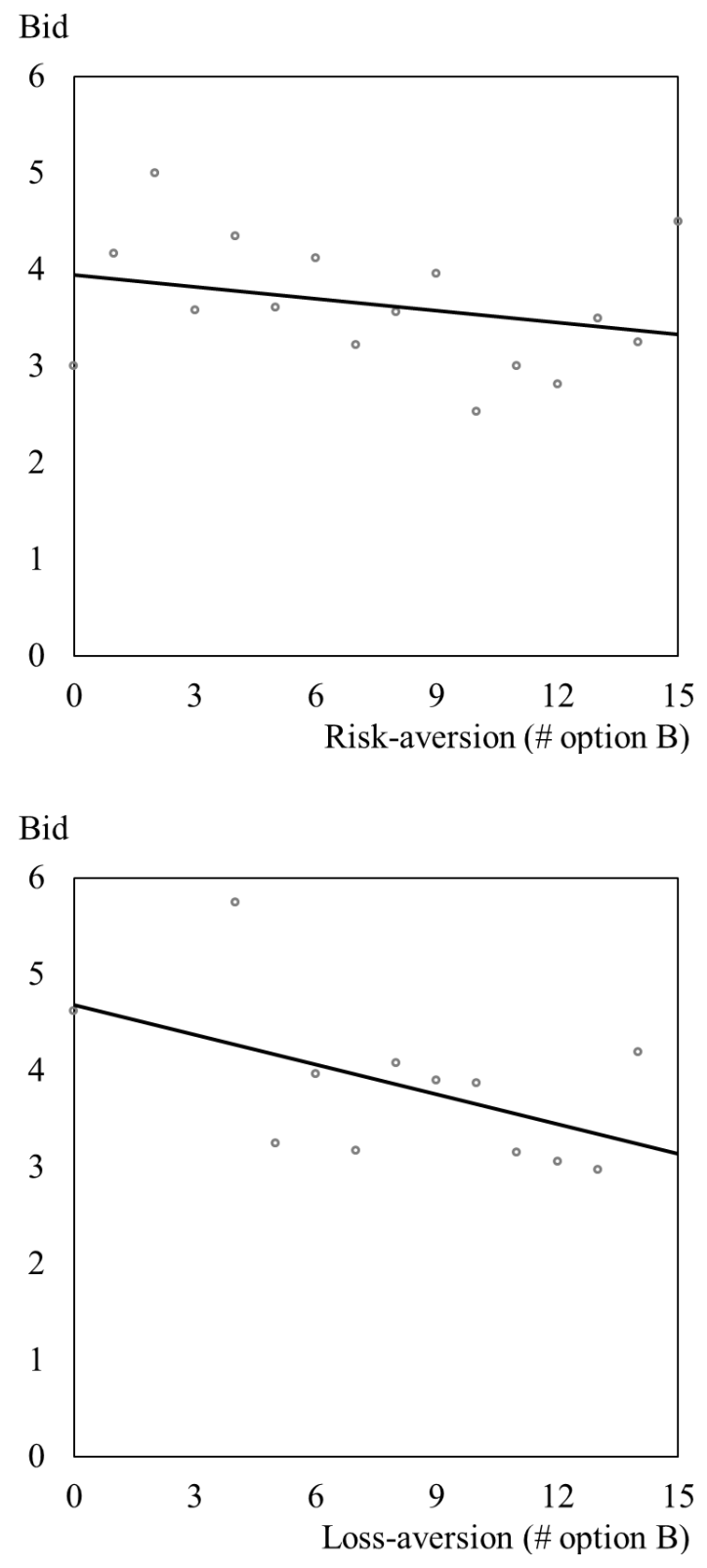
Figure 6: Bid for a zero prize versus bid for a positive prize.

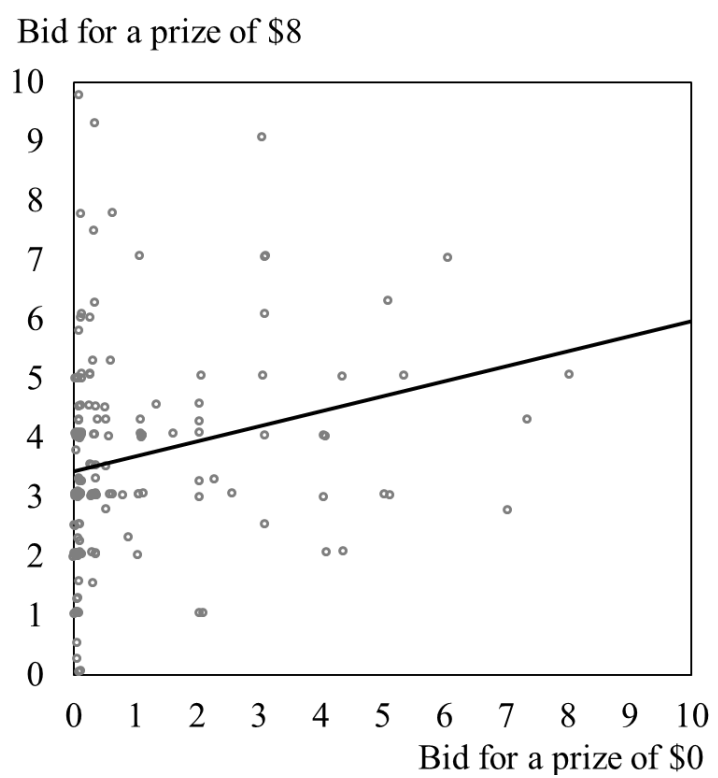


Figure 7: Average bid by CRT and GRE.
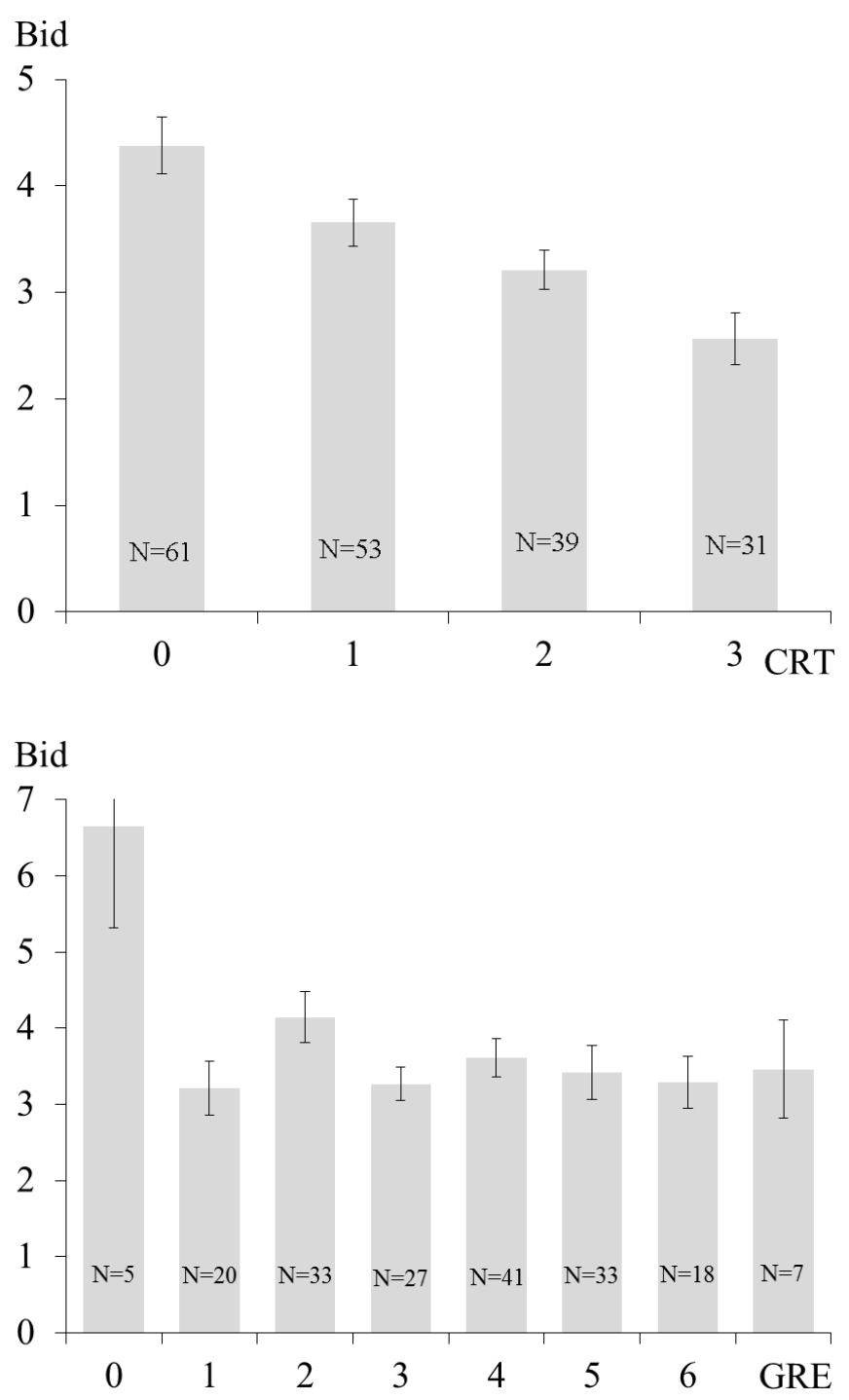


\section{Table 1: Summary of the experimental design.}

\begin{tabular}{|c|c|c|}
\hline Part & Measure & How measured \\
\hline \multirow[t]{2}{*}{1} & Quiz & 5 quiz questions about the contest, receiving $\$ 0.50$ for each correct answer. \\
\hline & Bid & $\begin{array}{l}\text { Bid between } \$ 0 \text { and } \$ 10 \text { (including increments of } \$ 0.25 \text { ) in a two-payer } \\
\text { contest for a reward of } \$ 8 \text {. }\end{array}$ \\
\hline 2 & Belief & $\begin{array}{l}\text { Guess about the bid of the other participant, receiving } \$ 2.00 \text { for a correct } \\
\text { guess. }\end{array}$ \\
\hline 3 & Bid for zero & $\begin{array}{l}\text { Bid between } \$ 0 \text { and } \$ 10 \text { (including increments of } \$ 0.25 \text { ) in a two-payer } \\
\text { contest for a reward of } \$ 0 .\end{array}$ \\
\hline 4 & Social preferences & $\begin{array}{l}12 \text { binary choices measuring social preferences, with each choice offering the } \\
\text { option of } \$ 3 \text { to both self and other or an unequal amount with total value } \\
\text { between } \$ 3.50 \text { and } \$ 8.50 \text {. }\end{array}$ \\
\hline \multirow[t]{2}{*}{5} & Ellsberg & $\begin{array}{l}\text { Two decision, First, between option A ( } \$ 5.00 \text { if a red ball is drawn) and option } \\
\text { B ( } \$ 5.00 \text { if a blue ball is drawn). Second, between option A ( } \$ 5.00 \text { if a red or } \\
\text { green ball is drawn) and option B ( } \$ 5.00 \text { if a blue or green ball is drawn). }\end{array}$ \\
\hline & Allais & $\begin{array}{l}\text { Two decisions. First, between option A (receiving } \$ 5.00 \text { for sure) and option } \\
\text { B ( } 89 \% \text { chance of receiving } \$ 5.00,1 \% \text { chance of receiving nothing, and } 10 \% \\
\text { chance of receiving } \$ 25.00) \text {. Second, between option A (89\% chance of } \\
\text { receiving nothing, and } 11 \% \text { chance of receiving } \$ 5.00) \text { and option B (90\% } \\
\text { chance of receiving nothing, and } 10 \% \text { chance of receiving } \$ 25.00) \text {. }\end{array}$ \\
\hline \multirow[t]{2}{*}{6} & Risk aversion & $\begin{array}{l}15 \text { binary choices between a risky option A ( } \$ 0 \text { or } \$ 5 \text { with } 50 \% \text { chance each) } \\
\text { and a safe option B (increasing monotonically from } \$ 0.50 \text { to } \$ 4 \text { ) }\end{array}$ \\
\hline & Loss aversion & $\begin{array}{l}15 \text { binary choices between a risky option A (50\% chance of receiving } \$ 5 \text { or } \\
\text { losing a certain amount between }-\$ 0.50 \text { to }-\$ 7.50) \text { and a safe option B of } \$ 0 \text {. }\end{array}$ \\
\hline 7 & CRT & 3 cognitive reflection questions, receiving $\$ 0.50$ for each correct answer. \\
\hline 8 & GRE & $\begin{array}{l}7 \text { multiple-choice GRE mathematical questions during } 10 \text { minutes, receiving } \\
\$ 0.50 \text { for each correct answer. }\end{array}$ \\
\hline
\end{tabular}


Table 2: Social preferences and bids.

\begin{tabular}{lcccccc}
\hline \hline $\begin{array}{l}\text { Decision } \\
\text { number }\end{array}$ & $\begin{array}{c}\text { Option A } \\
\text { (self, other) }\end{array}$ & $\begin{array}{c}\text { Option B } \\
\text { (self, other) }\end{array}$ & $\begin{array}{c}\text { Percentage } \\
\text { choosing A }\end{array}$ & $\begin{array}{c}\text { Average bid } \\
\text { conditional on A }\end{array}$ & $\begin{array}{c}\text { Average bid } \\
\text { conditional on B }\end{array}$ & $\begin{array}{c}\text { Wilcoxon } \\
\text { rank-sum test }\end{array}$ \\
\hline 1 & $\$ 3.00, \$ 3.00$ & $\$ 3.00, \$ 2.50$ & $87.0 \%$ & $3.57(0.14)$ & $4.00(0.30)$ & p-value $=0.08$ \\
2 & $\$ 3.00, \$ 3.00$ & $\$ 3.00, \$ 2.00$ & $83.2 \%$ & $3.52(0.15)$ & $4.13(0.25)$ & p-value $=0.01$ \\
3 & $\$ 3.00, \$ 3.00$ & $\$ 3.00, \$ 1.50$ & $83.2 \%$ & $3.51(0.15)$ & $4.16(0.24)$ & p-value $=0.01$ \\
\hline 4 & $\$ 3.00, \$ 3.00$ & $\$ 2.50, \$ 2.00$ & $95.7 \%$ & $3.65(0.14)$ & $3.00(0.46)$ & p-value $=0.33$ \\
5 & $\$ 3.00, \$ 3.00$ & $\$ 2.50, \$ 1.50$ & $96.2 \%$ & $3.60(0.14)$ & $4.14(0.59)$ & p-value $=0.30$ \\
6 & $\$ 3.00, \$ 3.00$ & $\$ 2.50, \$ 1.00$ & $94.6 \%$ & $3.58(0.14)$ & $4.35(0.56)$ & p-value $=0.15$ \\
\hline 7 & $\$ 3.00, \$ 3.00$ & $\$ 3.00, \$ 3.50$ & $45.7 \%$ & $3.88(0.21)$ & $3.41(0.16)$ & p-value $=0.14$ \\
8 & $\$ 3.00, \$ 3.00$ & $\$ 3.00, \$ 4.00$ & $46.7 \%$ & $3.90(0.20)$ & $3.39(0.17)$ & p-value $=0.05$ \\
9 & $\$ 3.00, \$ 3.00$ & $\$ 3.00, \$ 4.50$ & $46.7 \%$ & $3.87(0.20)$ & $3.41(0.17)$ & p-value $=0.09$ \\
\hline 10 & $\$ 3.00, \$ 3.00$ & $\$ 3.50, \$ 4.00$ & $17.9 \%$ & $4.25(0.40)$ & $3.49(0.13)$ & p-value $=0.05$ \\
11 & $\$ 3.00, \$ 3.00$ & $\$ 3.50, \$ 4.50$ & $21.7 \%$ & $4.18(0.35)$ & $3.47(0.14)$ & p-value $=0.06$ \\
12 & $\$ 3.00, \$ 3.00$ & $\$ 3.50, \$ 5.00$ & $22.3 \%$ & $4.19(0.34)$ & $3.46(0.14)$ & p-value $=0.04$ \\
\hline
\end{tabular}


Table 3: Correlation matrix.

\begin{tabular}{lccccccccc}
\hline \hline & bid & belief & quiz & Bias & risk-averse & loss-averse & bid-zero & competitive & gre \\
\hline belief & 0.31 & & & & & & & & \\
& $(0.00)$ & & & & & & & & \\
quiz & -0.25 & -0.16 & & & & & & & \\
& $(0.00)$ & $(0.02)$ & & & & & & & \\
bias & 0.05 & -0.00 & -0.09 & & & & & \\
& $(0.45)$ & $(0.98)$ & $(0.20)$ & & & & & \\
risk-averse & -0.03 & 0.09 & 0.08 & 0.03 & & & & \\
& $(0.66)$ & $(0.20)$ & $(0.24)$ & $(0.60)$ & & & & \\
loss-averse & -0.13 & -0.02 & -0.02 & 0.14 & 0.19 & & & \\
& $(0.06)$ & $(0.72)$ & $(0.75)$ & $(0.05)$ & $(0.00)$ & & & \\
bid-zero & 0.22 & 0.11 & -0.22 & -0.01 & -0.13 & -0.18 & & \\
& $(0.00)$ & $(0.12)$ & $(0.00)$ & $(0.89)$ & $(0.06)$ & $(0.01)$ & & & \\
competitive & 0.17 & 0.04 & -0.06 & 0.00 & -0.02 & -0.17 & 0.02 & & \\
& $(0.01)$ & $(0.56)$ & $(0.40)$ & $(0.93)$ & $(0.68)$ & $(0.01)$ & $(0.72)$ & & \\
gre & -0.14 & -0.14 & 0.15 & -0.07 & -0.08 & 0.01 & -0.04 & -0.19 & \\
& $(0.04)$ & $(0.05)$ & $(0.03)$ & $(0.31)$ & $(0.24)$ & $(0.80)$ & $(0.55)$ & $(0.00)$ & \\
crt & -0.35 & -0.09 & 0.26 & -0.06 & 0.05 & 0.05 & -0.28 & -0.31 & 0.35 \\
& $(0.00)$ & $(0.20)$ & $(0.00)$ & $(0.40)$ & $(0.43)$ & $(0.42)$ & $(0.00)$ & $(0.00)$ & $(0.00)$ \\
\hline
\end{tabular}

$\mathrm{p}$-values are in parentheses. 
Table 4: OLS regression of bid on measured behaviors.

\begin{tabular}{|c|c|c|c|c|c|c|}
\hline Specification & (1) & (2) & (3) & (4) & (5) & (6) \\
\hline \multicolumn{7}{|l|}{ Dependent variable, bid } \\
\hline belief & $0.31 * *$ & & & & & $0.28 * *$ \\
\hline [belief about the other bid] & $(0.13)$ & & & & & $(0.12)$ \\
\hline quiz & $-0.49 * * *$ & & & & & $-0.29 *$ \\
\hline [number of correct quiz answers] & $(0.19)$ & & & & & $(0.18)$ \\
\hline bias & & 0.26 & & & & 0.15 \\
\hline [violation of the expected utility] & & $(0.25)$ & & & & $(0.20)$ \\
\hline risk-averse & & 0.00 & & & & 0.00 \\
\hline [number of safe options B] & & $(0.05)$ & & & & $(0.04)$ \\
\hline loss-averse & & $-0.12^{* *}$ & & & & -0.08 \\
\hline $\begin{array}{l}\text { [number of options B] } \\
\text { bid-zero }\end{array}$ & & $(0.06)$ & & & & $(0.05)$ \\
\hline $\begin{array}{l}\text { bid-zero } \\
\text { [bid for a prize of } \$ 0]\end{array}$ & & & $\begin{array}{c}0.21 * * * \\
(0.07)\end{array}$ & & & $\begin{array}{c}0.07 \\
(0.08)\end{array}$ \\
\hline $\begin{array}{l}\text { competitive } \\
\text { [number of antisocial choices] }\end{array}$ & & & & $\begin{array}{l}0.10 * * \\
(0.04)\end{array}$ & & $\begin{array}{c}0.03 \\
(0.04)\end{array}$ \\
\hline $\begin{array}{l}\text { gre } \\
\text { [number of correct GRE answers] }\end{array}$ & & & & & $\begin{array}{l}-0.02 \\
(0.09)\end{array}$ & $\begin{array}{l}0.03 \\
(0.08)\end{array}$ \\
\hline $\begin{array}{l}\text { crt } \\
\text { [number of correct CRT answers] }\end{array}$ & & & & & $\begin{array}{c}-0.58 * * * \\
(0.13)\end{array}$ & $\begin{array}{c}-0.43 * * * \\
(0.13)\end{array}$ \\
\hline $\begin{array}{l}\text { constant } \\
\text { [the constant term] }\end{array}$ & $\begin{array}{c}4.29 * * * \\
(0.91)\end{array}$ & $\begin{array}{c}4.56^{* * * *} \\
(0.50)\end{array}$ & $\begin{array}{c}3.43 * * * \\
(0.14)\end{array}$ & $\begin{array}{c}3.35 * * * \\
(0.16)\end{array}$ & $\begin{array}{c}4.41 * * * \\
(0.35)\end{array}$ & $\begin{array}{c}4.61 * * * \\
(1.10)\end{array}$ \\
\hline$N$ & 184 & 184 & 184 & 184 & 184 & 184 \\
\hline$R$-squared & 0.14 & 0.02 & 0.05 & 0.03 & 0.13 & 0.25 \\
\hline$R$-squared adjusted & 0.13 & 0.01 & 0.05 & 0.03 & 0.12 & 0.21 \\
\hline
\end{tabular}

$*$ significant at $10 \%$, ** significant at $5 \%, * * *$ significant at $1 \%$. Robust standard errors are in parenthesis. 
Table 5: OLS regression of bid on measured behaviors, controlling for belief.

\begin{tabular}{|c|c|c|c|c|c|c|}
\hline Specification & (1) & (2) & (3) & (4) & 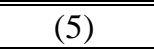 & (6) \\
\hline \multicolumn{7}{|l|}{ Dependent variable, bid } \\
\hline belief & $0.31 * *$ & $0.34 * * *$ & $0.32 * *$ & $0.34 * *$ & $0.31 * *$ & $0.28 * *$ \\
\hline [belief about the other bid] & $(0.13)$ & $(0.13)$ & $(0.13)$ & $(0.13)$ & $(0.12)$ & $(0.12)$ \\
\hline quiz & $-0.49 * * *$ & & & & & $-0.29 *$ \\
\hline [number of correct quiz answers] & $(0.19)$ & & & & & $(0.18)$ \\
\hline bias & & 0.26 & & & & 0.15 \\
\hline [violation of the expected utility] & & $(0.21)$ & & & & $(0.20)$ \\
\hline risk-averse & & -0.03 & & & & 0.00 \\
\hline [number of safe options B] & & $(0.04)$ & & & & $(0.04)$ \\
\hline loss-averse & & $-0.11 * *$ & & & & -0.08 \\
\hline [number of options B] & & $(0.05)$ & & & & $(0.05)$ \\
\hline bid-zero & & & $0.18 * *$ & & & 0.07 \\
\hline [bid for a prize of $\$ 0]$ & & & $(0.08)$ & & & $(0.08)$ \\
\hline competitive & & & & $0.10^{* *}$ & & 0.03 \\
\hline [number of antisocial choices] & & & & $(0.04)$ & & $(0.04)$ \\
\hline gre & & & & & 0.02 & 0.03 \\
\hline [number of correct GRE answers] & & & & & $(0.08)$ & $(0.08)$ \\
\hline $\begin{array}{l}\text { crt } \\
\text { [number of correct CRT answers] }\end{array}$ & & & & & $\begin{array}{c}-0.56^{* * * *} \\
(0.13)\end{array}$ & $\begin{array}{c}-0.43 * * * \\
(0.13)\end{array}$ \\
\hline constant & $4.29 * * *$ & $3.45^{* * *}$ & $2.37 * * *$ & $2.24 * * *$ & $3.20 * * *$ & $4.61 * * *$ \\
\hline [the constant term] & $(0.91)$ & $(0.76)$ & $(0.43)$ & $(0.46)$ & $(0.44)$ & $(1.10)$ \\
\hline$N$ & 184 & 184 & 184 & 184 & 184 & 184 \\
\hline$R$-squared & 0.14 & 0.13 & 0.14 & 0.13 & 0.21 & 0.25 \\
\hline$R$-squared adjusted & 0.13 & 0.11 & 0.13 & 0.12 & 0.2 & 0.21 \\
\hline
\end{tabular}

* significant at $10 \%, * *$ significant at $5 \%, * * *$ significant at $1 \%$. Robust standard errors are in parenthesis. 


\section{Table 6: OLS regression of bid on measured behaviors, controlling for CRT.}

\begin{tabular}{|c|c|c|c|c|c|c|}
\hline Specification & (1) & (2) & (3) & (4) & $(5)$ & (6) \\
\hline \multicolumn{7}{|l|}{ Dependent variable, bid } \\
\hline belief & $0.29 * *$ & & & & & $0.28 * *$ \\
\hline [belief about the other bid] & $(0.12)$ & & & & & $(0.12)$ \\
\hline quiz & $-0.31 *$ & & & & & $-0.29 *$ \\
\hline [number of correct quiz answers] & $(0.17)$ & & & & & $(0.18)$ \\
\hline bias & & 0.18 & & & & 0.15 \\
\hline [violation of the expected utility] & & $(0.24)$ & & & & $(0.20)$ \\
\hline risk-averse & & 0.01 & & & & 0.00 \\
\hline [number of safe options B] & & $(0.04)$ & & & & $(0.04)$ \\
\hline loss-averse & & $-0.10^{*}$ & & & & -0.08 \\
\hline [number of options B] & & $(0.05)$ & & & & $(0.05)$ \\
\hline bid-zero & & & $0.13 *$ & & & 0.07 \\
\hline [bid for a prize of $\$ 0$ ] & & & $(0.08)$ & & & $(0.08)$ \\
\hline competitive & & & & 0.04 & & 0.03 \\
\hline [number of antisocial choices] & & & & $(0.04)$ & & $(0.04)$ \\
\hline $\begin{array}{l}\text { gre } \\
\text { [number of correct GRE answers] }\end{array}$ & & & & & $\begin{array}{l}-0.02 \\
(0.09)\end{array}$ & $\begin{array}{l}0.03 \\
(0.08)\end{array}$ \\
\hline $\begin{array}{l}\text { crt } \\
\text { [number of correct CRT answers] }\end{array}$ & $\begin{array}{c}-0.50 * * * \\
(0.10)\end{array}$ & $\begin{array}{c}-0.58 * * * \\
(0.11)\end{array}$ & $\begin{array}{c}-0.53 * * * \\
(0.12)\end{array}$ & $\begin{array}{c}-0.56 * * * \\
(0.12)\end{array}$ & $\begin{array}{c}-0.58 * * * \\
(0.13)\end{array}$ & $\begin{array}{c}-0.43 * * * \\
(0.13)\end{array}$ \\
\hline constant & $4.33 * * *$ & $5.09 * * *$ & $4.15^{* * *}$ & $4.20 * * *$ & $4.41 * * *$ & $4.61 * * *$ \\
\hline [the constant term] & $(0.85)$ & $(0.50)$ & $(0.25)$ & $(0.27)$ & $(0.35)$ & $(1.10)$ \\
\hline$N$ & 184 & 184 & 184 & 184 & 184 & 184 \\
\hline$R$-squared & 0.23 & 0.15 & 0.15 & 0.13 & 0.13 & 0.25 \\
\hline$R$-squared adjusted & 0.21 & 0.13 & 0.14 & 0.12 & 0.12 & 0.21 \\
\hline
\end{tabular}

$*$ significant at $10 \%$, ** significant at 5\%, *** significant at 1\%. Robust standard errors are in parenthesis. 


\section{Appendix A (For Online Publication) - Experimental Instructions}

\section{GENERAL INSTRUCTIONS}

This is an experiment in the economics of decision-making. Various research agencies have provided funds for this research. The instructions are simple.

The experiment will proceed in 8 parts. Each part contains decision problems that require you to make a series of choices that determine your total earnings. The currency used in all parts of the experiment is U.S. Dollars. You have already received a $\$ 10.00$ participation fee. Your earnings from 8 parts of the experiment will be added to your participation fee. At the end of today's experiment, you will be paid in private and in cash.

It is very important that you remain silent and do not look at other people's work. If you have any questions, or need assistance of any kind, please raise your hand and an experimenter will come to you. If you talk, laugh, exclaim out loud, etc., you will be asked to leave and you will not be paid. We expect and appreciate your cooperation.

At this time we proceed to PART 1 of the experiment.

\section{PART 1}

In PART 1 of the experiment you will be randomly and anonymously matched with another participant. You and the other participant will choose how much to bid for a reward of \$8. You may bid any integer number of dollars between $\$ 0$ and $\$ 10$ (including increments of $\$ 0.25$ ).

After both participants have made their decisions, your earnings will be calculated. Regardless of who receives the reward, both participants will have to pay their bids. Thus, your earnings will be calculated as follows:

If you receive the reward: $\quad$ Earnings $=$ reward - your bid $=\$ 8-$ your bid

If you do not receive the reward: $\quad$ Earnings $=$ no reward - your bid $=\$ 0-$ your bid

Remember, you have received a $\$ 10$ participation fee. In this part of the experiment, you may receive either positive or negative earnings. If the earnings are negative, we will subtract them from your participation fee. If the earnings are positive, we will add them to your participation fee.

The more you bid, the more likely you are to receive the reward. The more the other participant bids, the less likely you are to receive the reward. Specifically, for each dollar you bid you will receive one lottery ticket. After both participants make their bids, the computer will draw randomly one ticket among the tickets purchased by you and the other participant. The owner of the drawn ticket will receive the reward of $\$ 8$. Thus, your chance of receiving the reward is given by the number of dollars you bid divided by the total number of dollars you and the other participant bid.

Your chance of receiving a reward

$$
=\frac{\text { your bid }}{\text { your bid }+ \text { the other participant's bid }}
$$

If both participants bid zero, the reward is randomly assigned to one of the two participants.

After both participants make their bids, the computer will make a random draw based on these bids and determine who receives the reward. Then the computer will calculate your earnings based on your bid and whether you received the reward or not.

Example: Assume that you bid $\$ 1$ and the other participant bids $\$ 3$. Therefore, the computer assigns 1 lottery ticket to you and 3 lottery tickets to the other participant. Then the computer randomly draws one lottery ticket out of $4(1+3)$. Thus, your chance of receiving the reward is $0.25=1 / 4$ and the other participant's chance is $0.75=3 / 4$. Also, assume that the computer made a random draw and the other participant has received the reward. Therefore, your earnings $=\$ 0-\$ 1=-\$ 1$, since you did not receive the reward and your bid was $\$ 1$. The other participant's earnings $=\$ 8-\$ 3=\$ 5$, since the reward was $\$ 8$ and the other participant's bid was $\$ 3$.

Important notes: You will not be told which of the participants in this room are matched with you. You can never guarantee yourself the reward. However, by increasing your bid, you can increase your chance of receiving the reward. Regardless of who receives the reward, both participants will have to pay their bids.

The actual earnings for this part of the experiment will be determined at the end of the experiment, and will be independent of other parts of the experiment.

QUIZ

Before you make your bid, you will be asked to answer 5 quiz questions during 5 minutes to check your understanding of the instructions. You will receive $\$ 0.50$ for each correct answer. All 5 questions are given to you below. However, you have to enter your final answers into the computer before the 5 minutes end to be able to get your earnings. 
Question 1: Assume that you bid $\$ 4$ and the other participant bids $\$ 1$. How many total lottery tickets will the computer use for drawing?

Question 2: Assume that you bid $\$ 4$ and the other participant bids $\$ 1$. What is your chance of receiving the reward?

Question 3: Assume that you bid $\$ 4$ and the other participant bids $\$ 1$. Also, assume that the computer made a random draw and the other participant has received the reward. What are your earnings?

Question 4: If you knew that the other participant bid $\$ 0$, which bid would bring you the highest earnings for sure: $\$ 0, \$ 1, \$ 2, \$ 3, \$ 4, \$ 5, \$ 6, \$ 7, \$ 8, \$ 9$ or $\$ 10$ ?

Question 5: If you knew that the other participant bid $\$ 2$, which bid would bring you the highest expected earnings: $\$ 0, \$ 1, \$ 2, \$ 3, \$ 4, \$ 5, \$ 6, \$ 7, \$ 8, \$ 9$ or $\$ 10$ ?

\section{PART 2}

In PART 2 of the experiment, you will be asked to provide a guess about what was the bid made by the other participant in PART 1. You will receive $\$ 2$ if your guess is equal to the bid made by the other participant.

The actual earnings for this part of the experiment will be determined at the end of the experiment, and will be independent of other parts of the experiment.

Please enter your guess on your screen.

\section{PART 3}

In PART 3 of the experiment you will be randomly and anonymously matched with another participant. The rules for PART 3 are the same as the rules for PART 1. You and the other participant will choose how much to bid in order to be a winner. The only difference is that in PART 3 the winner does not receive the reward. Therefore, the reward is worth $\$ 0$ to you and the other participant. After both participants have made their decisions, your earnings will be calculated as follows.

Earnings $=\$ 0-$ your bid

After both participants make their bids, the computer will make a random draw based on these bids and determine who the winner is. At the end of the experiment, the computer will display the results of this part of the experiment (that is, whether you won or not), and will calculate your earnings.

Please make your decision on your screen.

\section{PART 4}

In PART 4 of the experiment, you will be asked to make a series of choices in decision problems. You will see a table with 12 lines. You will state whether you prefer Option A or Option B in each line. You should think of each line as a separate decision you need to make. However, only one line will be the 'line that counts' and will be paid out. In particular, at the end of the experiment, the computer will randomly draw an integer number between 1 and 12. The number chosen indicates which line will be paid out.

Your earnings for the selected line depend on which option you chose: if you chose A in that line, you will receive \$3.00 and the other participant who will be matched with you will also receive \$3.00. If you chose B in that line, you and the other participant will receive earnings as indicated in the table for that specific line. For example, if you chose B in line 2 and this line is selected for payment, you will receive $\$ 3.00$ and the other participant will receive $\$ 2.00$. Similarly, if you chose B in line 3 and this line is selected for payment, you will receive $\$ 3.00$ and the other participant will receive $\$ 1.50$.

After you have completed all your choices the computer will randomly draw an integer numbered between 1 and 12 to determine which line is going to be paid. Then the computer will randomly and anonymously match you with another participant in the experiment. While matching you with another participant, the computer will also randomly determine whose decision to implement. If the computer chooses your decision to implement, then the earnings to you and the other participant will be determined according to your choice of A or B. If the computer chooses the other participant decision to implement, then the earnings will determined according to the other participant choice of A or B. 


\begin{tabular}{|c||l||l||c|}
\hline $\begin{array}{c}\text { Decision } \\
\text { Number }\end{array}$ & $\begin{array}{c}\text { Option } \mathrm{A} \\
\text { (you, the other participant) }\end{array}$ & $\begin{array}{c}\text { Option } \mathrm{B} \\
\text { (you, the other participant) }\end{array}$ & $\begin{array}{c}\text { Choose } \\
\text { A or B }\end{array}$ \\
\hline 1 & $\$ 3.00$ to you, $\$ 3.00$ to other & $\$ 3.00$ to you, $\$ 2.50$ to other \\
\hline 2 & $\$ 3.00$ to you, $\$ 3.00$ to other & $\$ 3.00$ to you, $\$ 2.00$ to other \\
\hline 3 & $\$ 3.00$ to you, $\$ 3.00$ to other & $\$ 3.00$ to you, $\$ 1.50$ to other & \\
\hline 4 & $\$ 3.00$ to you, $\$ 3.00$ to other & $\$ 2.50$ to you, $\$ 2.00$ to other & \\
\hline 5 & $\$ 3.00$ to you, $\$ 3.00$ to other & $\$ 2.50$ to you, $\$ 1.50$ to other \\
\hline 6 & $\$ 3.00$ to you, $\$ 3.00$ to other & $\$ 2.50$ to you, $\$ 1.00$ to other & \\
\hline 7 & $\$ 3.00$ to you, $\$ 3.00$ to other & $\$ 3.00$ to you, $\$ 3.50$ to other & \\
\hline 8 & $\$ 3.00$ to you, $\$ 3.00$ to other & $\$ 3.00$ to you, $\$ 4.00$ to other \\
\hline 9 & $\$ 3.00$ to you, $\$ 3.00$ to other & $\$ 3.00$ to you, $\$ 4.50$ to other & \\
\hline 10 & $\$ 3.00$ to you, $\$ 3.00$ to other & $\$ 3.50$ to you, $\$ 4.00$ to other \\
\hline 11 & $\$ 3.00$ to you, $\$ 3.00$ to other & $\$ 3.50$ to you, $\$ 4.50$ to other \\
\hline 12 & $\$ 3.00$ to you, $\$ 3.00$ to other & $\$ 3.50$ to you, $\$ 5.00$ to other \\
\hline
\end{tabular}

The actual earnings for this part of the experiment will be determined at the end of the experiment, and will be independent of other parts of the experiment.

Please make your decision on your screen.

\section{PART 5}

In PART 5 of the experiment, you will be asked to make a series of choices in decision problems. How much you receive will depend partly on chance and partly on the choices you make.

You will see two tables with 2 lines each. You will state whether you prefer Option A or Option B in each line. You should think of each line as a separate decision you need to make. You will make 4 decisions in total. However, only one line will be the 'line that counts' and will be paid out. In particular, at the end of the experiment, the computer will randomly draw an integer number between 1 and 4 . The number chosen indicates which line will be paid out. You will be paid according to the option you selected on that line.

The decisions you make in the first table (lines 1-2) correspond to the following problem: There is bag containing 30 red balls and 60 other balls that are either blue or green. You don't know how many blue or green balls there are, but that the total number of blue balls plus the total number of green equals 60 . The balls are well mixed so that each individual ball is as likely to be drawn as any other. In line 1, you are asked to choose between A or B. If you chose $\mathrm{A}$ in line 1 , you will receive $\$ 5.00$ if a red ball is drawn from the bag. If you chose B in line 1 , you will receive $\$ 5.00$ if a blue ball is drawn from the bag. In line 2, you are asked to choose between $\mathrm{A}$ or B. If you chose $\mathrm{A}$ in line 2, you will receive $\$ 5.00$ if a red or green ball is drawn from the bag. If you chose B in line 2 , you will receive $\$ 5.00$ if a blue or green ball is drawn from the bag.

\begin{tabular}{|c|c|c|c|}
\hline $\begin{array}{l}\text { Decision } \\
\text { Number }\end{array}$ & Option A & Option B & $\begin{array}{l}\text { Choose } \\
\text { A or B }\end{array}$ \\
\hline 1 & $\begin{array}{l}\$ 5.00 \text { if a red ball } \\
\text { is drawn from the bag }\end{array}$ & $\begin{array}{l}\$ 5.00 \text { if a blue ball } \\
\text { is drawn from the bag }\end{array}$ & \\
\hline 2 & $\begin{array}{l}\$ 5.00 \text { if a red or green ball } \\
\text { is drawn from the bag }\end{array}$ & $\begin{array}{l}\$ 5.00 \text { if a blue or green ball } \\
\text { is drawn from the bag }\end{array}$ & \\
\hline
\end{tabular}

The decisions you make in the second table (lines 3-4) are following: In line 3, you are asked to choose between $\mathrm{A}$ or B. If you chose $\mathrm{A}$ in line 3, you will receive $\$ 5.00$ for sure. If you chose B in line 3 , there is an $89 \%$ chance that you will receive $\$ 5.00$, a $1 \%$ chance that you will receive nothing, and a $10 \%$ chance that you will receive $\$ 25.00$. In line 4 , you are asked to choose between A or B. If you chose A in line 4 , there is an $89 \%$ chance that you will receive nothing, an $11 \%$ chance that you will receive $\$ 5.00$. If you chose B in line 4 , there is a $90 \%$ chance that you will receive nothing, a $10 \%$ chance that you will receive $\$ 25.00$. 


\begin{tabular}{|c||l||l||c|}
\hline $\begin{array}{c}\text { Decision } \\
\text { Number }\end{array}$ & \multicolumn{1}{|c||}{ Option A } & \multicolumn{1}{c|}{ Option B } & \multicolumn{1}{c|}{$\begin{array}{c}\text { Choose } \\
\text { A or B }\end{array}$} \\
\hline \multirow{3}{*}{3} & \$5.00 for sure & $\begin{array}{l}\text { \$5.00 with an } 89 \% \text { chance, } \\
\text { nothing with a } 1 \% \text { chance, and } \\
\$ 25.00 \text { with a } 10 \% \text { chance }\end{array}$ \\
\hline 4 & $\begin{array}{l}\text { nothing with an } 89 \% \text { chance, and } \\
\text { \$5 with an } 11 \% \text { chance }\end{array}$ & $\begin{array}{l}\text { nothing with a } 90 \% \text { chance, and } \\
\$ 25.00 \text { with a } 10 \% \text { chance }\end{array}$ & \\
\hline
\end{tabular}

The actual earnings for this part of the experiment will be determined at the end of the experiment, and will be independent of other parts of the experiment.

Please make your decisions on your screen.

\section{PART 6}

In PART 6 of the experiment, you will be asked to make a series of choices in decision problems. How much you receive will depend partly on chance and partly on the choices you make.

You will see two tables with 15 lines each. You will state whether you prefer Option A or Option B in each line. You should think of each line as a separate decision you need to make. You will make 30 decisions in total. However, only one line will be the 'line that counts' and will be paid out. In particular, at the end of the experiment, the computer will randomly draw an integer number between 1 and 30. The number chosen indicates which line will be paid out. You will be paid according to the option you selected on that line.

Your earnings for the selected line depend on which option you chose: In the first table (lines 1-15), option A always offers a $50 \%$ chance to receive $\$ 5.00$ and a $50 \%$ chance to receive nothing, while option B offers a certain amount of money for sure (between $\$ 0.50$ and $\$ 4.00$, depending on the line). If you choose $\mathrm{B}$, you will receive a certain amount of money for sure specified by that line. If you chose A in that line, you will receive either $\$ 5.00$ or nothing. To determine your earnings in the case you chose A we will randomly draw a ball from a bag containing ten orange balls and ten white balls. That means that when we draw a ball, there is a $50 \%$ chance that it is white and a $50 \%$ chance that it is orange. If the drawn ball is white and you selected $\mathrm{A}$ in that line, you will receive $\$ 5.00$, otherwise you will receive $\$ 0.00$.

\begin{tabular}{|c|c|c|c|c|}
\hline $\begin{array}{l}\text { Decision } \\
\text { Number }\end{array}$ & \multicolumn{2}{|c|}{ Option A } & Option B & $\begin{array}{c}\text { Choose } \\
\text { A or B }\end{array}$ \\
\hline 1 & $\$ 5.00$ with a $50 \%$ chance & nothing with a $50 \%$ chance & $\$ 0.50$ for sure & \\
\hline 2 & $\$ 5.00$ with a $50 \%$ chance & nothing with a $50 \%$ chance & $\$ 0.75$ for sure & \\
\hline 3 & $\$ 5.00$ with a $50 \%$ chance & nothing with a $50 \%$ chance & $\$ 1.00$ for sure & \\
\hline 4 & $\$ 5.00$ with a $50 \%$ chance & nothing with a $50 \%$ chance & $\$ 1.25$ for sure & \\
\hline 5 & $\$ 5.00$ with a $50 \%$ chance & nothing with a $50 \%$ chance & $\$ 1.50$ for sure & \\
\hline 6 & $\$ 5.00$ with a $50 \%$ chance & nothing with a $50 \%$ chance & $\$ 1.75$ for sure & \\
\hline 7 & $\$ 5.00$ with a $50 \%$ chance & nothing with a $50 \%$ chance & $\$ 2.00$ for sure & \\
\hline 8 & $\$ 5.00$ with a $50 \%$ chance & nothing with a $50 \%$ chance & $\$ 2.25$ for sure & \\
\hline 9 & $\$ 5.00$ with a $50 \%$ chance & nothing with a $50 \%$ chance & $\$ 2.50$ for sure & \\
\hline 10 & $\$ 5.00$ with a $50 \%$ chance & nothing with a $50 \%$ chance & $\$ 2.75$ for sure & \\
\hline 11 & $\$ 5.00$ with a $50 \%$ chance & nothing with a $50 \%$ chance & $\$ 3.00$ for sure & \\
\hline 12 & $\$ 5.00$ with a $50 \%$ chance & nothing with a $50 \%$ chance & $\$ 3.25$ for sure & \\
\hline 13 & $\$ 5.00$ with a $50 \%$ chance & nothing with a $50 \%$ chance & $\$ 3.50$ for sure & \\
\hline 14 & $\$ 5.00$ with a $50 \%$ chance & nothing with a $50 \%$ chance & $\$ 3.75$ for sure & \\
\hline 15 & $\$ 5.00$ with a $50 \%$ chance & nothing with a $50 \%$ chance & $\$ 4.00$ for sure & \\
\hline
\end{tabular}

In the second table (lines 16-30), option A offers a 50\% chance to receive $\$ 5.00$ and a $50 \%$ chance to lose a certain amount of money (between $-\$ 0.50$ and $-\$ 7.50$, depending on the line), while option B offers $\$ 0.00$ for sure. If you chose $\mathrm{B}$, you will receive $\$ 0.00$. If you chose option A in that line, you can receive either a loss between $-\$ 0.50$ and $-\$ 7.50$, depending on the line, or a gain of $\$ 5.00$. To determine your earnings in the case you chose option A we will randomly draw a ball from a bag containing ten orange and ten white balls. If the drawn ball is white and you 
selected $\mathrm{A}$ in that line, you will receive $\$ 5.00$, otherwise you will receive $-\$ \mathrm{x}$ (the exact amount depends on the line chosen).

\begin{tabular}{|c|c|c|c|c|}
\hline $\begin{array}{l}\text { Decision } \\
\text { Number }\end{array}$ & \multicolumn{2}{|c|}{ Option A } & Option B & $\begin{array}{l}\text { Choose } \\
\text { A or B }\end{array}$ \\
\hline 16 & $\$ 5.00$ with a $50 \%$ chance & $-\$ 0.50$ with a $50 \%$ chance & $\$ 0.00$ for sure & \\
\hline 17 & $\$ 5.00$ with a $50 \%$ chance & -\$1.00 with a $50 \%$ chance & $\$ 0.00$ for sure & \\
\hline 18 & $\$ 5.00$ with a $50 \%$ chance & $-\$ 1.50$ with a $50 \%$ chance & $\$ 0.00$ for sure & \\
\hline 19 & $\$ 5.00$ with a $50 \%$ chance & -\$2.00 with a $50 \%$ chance & $\$ 0.00$ for sure & \\
\hline 20 & $\$ 5.00$ with a $50 \%$ chance & $-\$ 2.50$ with a $50 \%$ chance & $\$ 0.00$ for sure & \\
\hline 21 & $\$ 5.00$ with a $50 \%$ chance & -\$3.00 with a $50 \%$ chance & $\$ 0.00$ for sure & \\
\hline 22 & $\$ 5.00$ with a $50 \%$ chance & $-\$ 3.50$ with a $50 \%$ chance & $\$ 0.00$ for sure & \\
\hline 23 & $\$ 5.00$ with a $50 \%$ chance & $-\$ 4.00$ with a $50 \%$ chance & $\$ 0.00$ for sure & \\
\hline 24 & $\$ 5.00$ with a $50 \%$ chance & $-\$ 4.50$ with a $50 \%$ chance & $\$ 0.00$ for sure & \\
\hline 25 & $\$ 5.00$ with a $50 \%$ chance & $-\$ 5.00$ with a $50 \%$ chance & $\$ 0.00$ for sure & \\
\hline 26 & $\$ 5.00$ with a $50 \%$ chance & $-\$ 5.50$ with a $50 \%$ chance & $\$ 0.00$ for sure & \\
\hline 27 & $\$ 5.00$ with a $50 \%$ chance & $-\$ 6.00$ with a $50 \%$ chance & $\$ 0.00$ for sure & \\
\hline 28 & $\$ 5.00$ with a $50 \%$ chance & -\$6.50 with a $50 \%$ chance & $\$ 0.00$ for sure & \\
\hline 29 & $\$ 5.00$ with a $50 \%$ chance & $-\$ 7.00$ with a $50 \%$ chance & $\$ 0.00$ for sure & \\
\hline 30 & $\$ 5.00$ with a $50 \%$ chance & $-\$ 7.50$ with a $50 \%$ chance & $\$ 0.00$ for sure & \\
\hline
\end{tabular}

The actual earnings for this part of the experiment will be determined at the end of the experiment, and will be independent of other parts of the experiment.

Please make your decisions on your screen.

\section{PART 7}

In PART 7 of the experiment, you will be asked to answer 3 questions. You will receive $\$ 0.50$ per each correct answer, and there is no penalty for incorrect answers.

Question 1: A bat and a ball cost $\$ 1.10$ in total. The bat costs $\$ 1.00$ more than the ball. How much does the ball cost? ___ cents

Question 2: It takes 5 machines 5 minutes to make 5 widgets. How long does it take 100 machines to make 100 widgets? minutes

Question 3: In a lake, there is a patch of lily pads. Every day, the patch doubles in size. It takes 48 days for the patch to cover the entire lake. How long does it take for the patch to cover half of the lake? days

\section{PART 8}

In PART 8 of the experiment, you will take a 10-minute cognitive test containing 7 questions. You may use the margins of this booklet to work out your answer if needed. You may ONLY use pencil and paper provided. No other aids are permitted.

You will receive $\$ 0.50$ per each correct answer, and there is no penalty for incorrect answers.

All 7 questions are given to you in paper sheets. However, you have to enter your final answers into the computer before the 10 minutes end to be able to get your earnings.

Question 1: If the average (arithmetic mean) of 12 numbers is 25 and the average (arithmetic mean) of 11 of the numbers is 20 then what is the remaining number?

1. 5

2. 55

3. 60

4. 70

5. 80 
Question 2: If $b c \neq 0$, and $3 b+2 c=18$, then which of the following is NOT a possible value of $c$ ?

1. $5 \frac{3}{5}$

2. 6

3. $8 \frac{2}{5}$

4. 9

5. 12

Question 3: If $x$ is a positive integer greater than one, which of the following has the greatest value?

1. $\frac{1}{x}$

2. $\frac{1}{x+1}$

3. $\frac{x}{x+1}$

4. $\frac{x}{\left(\frac{1}{x+1}\right)}$

5. $\frac{x}{\left(\frac{x}{x+1}\right)}$

Question 4: A hat contains 18 raffle tickets, numbered 1 through 18. If two raffle tickets are chosen at random from the hat, what is the probability that both tickets are even numbers?

1. $\frac{2}{9}$

2. $\frac{4}{17}$

3. $\frac{1}{4}$

4. $\frac{1}{2}$

5. $\frac{33}{34}$

Question 5: What is the value of $\frac{3}{\left(\frac{3}{4}\right)}-\frac{\left(\frac{3}{2}\right)}{3}$ ?

1. -1.75

2. -0.75

3. 1

4. 2

5. 3.5

Question 6: A number divisible by a positive even prime number must be

1. prime

2. odd

3. even

4. the square of a prime

5. the square an odd number

Question 7: Which of the following inequalities is true?

1. $\frac{1}{11}<0.08<\frac{1}{9}$

2. $\frac{1}{10}<0.11<\frac{1}{8}$

3. $\frac{1}{7}<0.17<\frac{1}{6}$

4. $\frac{1}{5}<0.26<\frac{1}{4}$

5. $\frac{1}{3}<0.30<\frac{1}{2}$ 


\section{Appendix B (For Online Publication) - Additional Analysis}

Table B1 shows the 12 choices which we used to elicited social preferences and the corresponding CRT measures conditional on choosing A or B. Examining choices 1-6, we see that participants who choose option B, indicating competitive behavior (i.e., choosing to sacrifice social welfare to have a higher payoff than the opponent), are more impulsive (i.e., they score less on the CRT). Similarly, participants who choose A in 7-12, again indicating more competitive preferences, are more impulsive.

Table B1: Social preferences and CRT.

\begin{tabular}{lcccccc}
\hline \hline $\begin{array}{l}\text { Decision } \\
\text { Number }\end{array}$ & $\begin{array}{c}\text { Option A } \\
\text { (self, other) }\end{array}$ & $\begin{array}{c}\text { Option B } \\
\text { (self, other) }\end{array}$ & $\begin{array}{c}\text { Percentage } \\
\text { choosing A }\end{array}$ & $\begin{array}{c}\text { CRT } \\
\text { conditional on A }\end{array}$ & $\begin{array}{c}\text { CRT } \\
\text { conditional on B }\end{array}$ & $\begin{array}{c}\text { Wilcoxon } \\
\text { rank-sum test }\end{array}$ \\
\hline 1 & $\$ 3.00, \$ 3.00$ & $\$ 3.00, \$ 2.50$ & $87.0 \%$ & $1.25(0.08)$ & $0.95(0.22)$ & p-value $=0.17$ \\
2 & $\$ 3.00, \$ 3.00$ & $\$ 3.00, \$ 2.00$ & $83.2 \%$ & $1.28(0.08)$ & $0.87(0.18)$ & p-value $=0.04$ \\
3 & $\$ 3.00, \$ 3.00$ & $\$ 3.00, \$ 1.50$ & $83.2 \%$ & $1.29(0.08)$ & $0.83(0.19)$ & p-value $=0.02$ \\
\hline 4 & $\$ 3.00, \$ 3.00$ & $\$ 2.50, \$ 2.00$ & $95.7 \%$ & $1.23(0.08)$ & $0.75(0.25)$ & p-value $=0.25$ \\
5 & $\$ 3.00, \$ 3.00$ & $\$ 2.50, \$ 1.50$ & $96.2 \%$ & $1.24(0.08)$ & $0.42(0.20)$ & p-value $=0.05$ \\
6 & $\$ 3.00, \$ 3.00$ & $\$ 2.50, \$ 1.00$ & $94.6 \%$ & $1.27(0.08)$ & $0.30(0.15)$ & p-value $<0.01$ \\
\hline 7 & $\$ 3.00, \$ 3.00$ & $\$ 3.00, \$ 3.50$ & $45.7 \%$ & $0.85(0.10)$ & $1.52(0.11)$ & p-value $<0.01$ \\
8 & $\$ 3.00, \$ 3.00$ & $\$ 3.00, \$ 4.00$ & $46.7 \%$ & $0.86(0.10)$ & $1.53(0.11)$ & p-value $<0.01$ \\
9 & $\$ 3.00, \$ 3.00$ & $\$ 3.00, \$ 4.50$ & $46.7 \%$ & $0.86(0.10)$ & $1.53(0.11)$ & p-value $<0.01$ \\
\hline 10 & $\$ 3.00, \$ 3.00$ & $\$ 3.50, \$ 4.00$ & $17.9 \%$ & $0.66(0.14)$ & $1.33(0.08)$ & p-value $<0.01$ \\
11 & $\$ 3.00, \$ 3.00$ & $\$ 3.50, \$ 4.50$ & $21.7 \%$ & $0.72(0.14)$ & $1.35(0.09)$ & p-value $<0.01$ \\
12 & $\$ 3.00, \$ 3.00$ & $\$ 3.50, \$ 5.00$ & $22.3 \%$ & $0.75(0.14)$ & $1.34(0.09)$ & p-value $<0.01$ \\
\hline
\end{tabular}


Table B2 shows the estimation results of different OLS regressions in which the dependent variable is overbidding (i.e., the difference between the actual bid and the bestresponse calculated based on the stated belief about the other bid), and the independent variables are measured behaviors reported in Table 3. The estimation results are very similar qualitatively to those reported in Table 4.

Table B2: OLS regression of overbidding on measured behaviors.

\begin{tabular}{|c|c|c|c|c|c|c|}
\hline Specification & (1) & (2) & (3) & (4) & (5) & (6) \\
\hline \multicolumn{7}{|l|}{ Dependent variable, overbidding } \\
\hline $\begin{array}{l}\text { Quiz } \\
\text { [number of correct quiz answers] }\end{array}$ & $\begin{array}{c}-0.65 * * * \\
(0.23)\end{array}$ & & & & & $\begin{array}{l}-0.42^{*} \\
(0.22)\end{array}$ \\
\hline $\begin{array}{l}\text { Bias } \\
\text { [violation of the expected utility] }\end{array}$ & & $\begin{array}{c}0.24 \\
(0.31)\end{array}$ & & & & $\begin{array}{c}0.10 \\
(0.27)\end{array}$ \\
\hline $\begin{array}{l}\text { risk-averse } \\
\text { [number of safe options B] }\end{array}$ & & $\begin{array}{l}-0.01 \\
(0.05)\end{array}$ & & & & $\begin{array}{c}0.02 \\
(0.05)\end{array}$ \\
\hline $\begin{array}{l}\text { loss-averse } \\
\text { [number of options B] }\end{array}$ & & $\begin{array}{l}-0.11^{*} \\
(0.06)\end{array}$ & & & & $\begin{array}{l}-0.08 \\
(0.06)\end{array}$ \\
\hline $\begin{array}{l}\text { bid-zero } \\
{[\text { bid for a prize of } \$ 0]}\end{array}$ & & & $\begin{array}{c}0.22 * * * \\
(0.07)\end{array}$ & & & $\begin{array}{c}0.10 \\
(0.08)\end{array}$ \\
\hline $\begin{array}{l}\text { Competitive } \\
\text { [number of antisocial choices] }\end{array}$ & & & & $\begin{array}{l}0.10 * * \\
(0.05)\end{array}$ & & $\begin{array}{c}0.03 \\
(0.05)\end{array}$ \\
\hline $\begin{array}{l}\text { Gre } \\
\text { [number of correct GRE answers] }\end{array}$ & & & & & $\begin{array}{l}-0.06 \\
(0.10)\end{array}$ & $\begin{array}{l}-0.04 \\
(0.10)\end{array}$ \\
\hline $\begin{array}{l}\text { Crt } \\
\text { [number of correct CRT answers] }\end{array}$ & & & & & $\begin{array}{c}-0.58 * * * \\
(0.13)\end{array}$ & $\begin{array}{c}-0.42 * * * \\
(0.14)\end{array}$ \\
\hline $\begin{array}{l}\text { Constant } \\
\text { [the constant term] }\end{array}$ & $\begin{array}{c}4.26 * * * \\
(0.85) \\
\end{array}$ & $\begin{array}{c}2.91 * * * \\
(0.54) \\
\end{array}$ & $\begin{array}{c}1.78^{* * * *} \\
(0.15)\end{array}$ & $\begin{array}{c}1.73 * * * \\
(0.18)\end{array}$ & $\begin{array}{c}2.90 * * * \\
(0.40)\end{array}$ & $\begin{array}{c}4.54 * * * \\
(1.06)\end{array}$ \\
\hline$N$ & 184 & 184 & 184 & 184 & 184 & 184 \\
\hline$R$-squared & 0.06 & 0.02 & 0.05 & 0.02 & 0.11 & 0.17 \\
\hline$R$-squared adjusted & 0.06 & 0 & 0.04 & 0.02 & 0.11 & 0.13 \\
\hline
\end{tabular}

* significant at $10 \%, * *$ significant at $5 \%, * * *$ significant at $1 \%$.

Robust standard errors are in parenthesis. 
Table B3 shows the estimation results of different OLS regressions in which the dependent variable is expected payoff (i.e., the average expected payoff calculated based on the individual bid and the empirical distribution of all other bids in our sample), and the independent variables are measured behaviors reported in Table 3. The estimation results are very similar qualitatively to those reported in Table 4.

Table B3: OLS regression of expected payoff on measured behaviors.

\begin{tabular}{|c|c|c|c|c|c|c|}
\hline Specification & (1) & (2) & (3) & (4) & (5) & (6) \\
\hline \multicolumn{7}{|l|}{ Dependent variable, expected payoff } \\
\hline $\begin{array}{l}\text { Belief } \\
\text { [belief about the other bid] }\end{array}$ & $\begin{array}{c}-0.16^{* *} \\
(0.06)\end{array}$ & & & & & $\begin{array}{c}-0.15 * * \\
(0.06)\end{array}$ \\
\hline $\begin{array}{l}\text { Quiz } \\
\text { [number of correct quiz answers] }\end{array}$ & $\begin{array}{c}0.26^{* *} \\
(0.10)\end{array}$ & & & & & $\begin{array}{l}0.17^{*} \\
(0.10)\end{array}$ \\
\hline $\begin{array}{l}\text { bias } \\
\text { [violation of the expected utility] }\end{array}$ & & $\begin{array}{l}-0.20 \\
(0.15)\end{array}$ & & & & $\begin{array}{l}-0.15 \\
(0.11)\end{array}$ \\
\hline $\begin{array}{l}\text { risk-averse } \\
\text { [number of safe options B] }\end{array}$ & & $\begin{array}{c}0.00 \\
(0.03)\end{array}$ & & & & $\begin{array}{l}-0.01 \\
(0.02)\end{array}$ \\
\hline $\begin{array}{l}\text { loss-averse } \\
\text { [number of options B] }\end{array}$ & & $\begin{array}{l}0.05^{*} \\
(0.03)\end{array}$ & & & & $\begin{array}{c}0.04 \\
(0.02)\end{array}$ \\
\hline $\begin{array}{l}\text { bid-zero } \\
\text { [bid for a prize of } \$ 0]\end{array}$ & & & $\begin{array}{c}-0.10 * * \\
(0.04)\end{array}$ & & & $\begin{array}{l}-0.03 \\
(0.05)\end{array}$ \\
\hline $\begin{array}{l}\text { competitive } \\
\text { [number of antisocial choices] }\end{array}$ & & & & $\begin{array}{c}-0.04 * * \\
(0.02)\end{array}$ & & $\begin{array}{l}-0.01 \\
(0.02)\end{array}$ \\
\hline $\begin{array}{l}\text { gre } \\
\text { [number of correct GRE answers] }\end{array}$ & & & & & $\begin{array}{l}0.03 \\
(0.05)\end{array}$ & $\begin{array}{c}0.00 \\
(0.04)\end{array}$ \\
\hline [number of correct CRT answers] & & & & & $\begin{array}{c}0.24 * * * \\
(0.06)\end{array}$ & $\begin{array}{c}0.16^{* *} \\
(0.07)\end{array}$ \\
\hline $\begin{array}{l}\text { constant } \\
\text { [the constant term] }\end{array}$ & $\begin{array}{l}-0.20 \\
(0.46)\end{array}$ & $\begin{array}{l}-0.15 \\
(0.26)\end{array}$ & $\begin{array}{c}0.24 * * * \\
(0.07)\end{array}$ & $\begin{array}{c}0.27 * * * \\
(0.08)\end{array}$ & $\begin{array}{l}-0.25 \\
(0.21)\end{array}$ & $\begin{array}{l}-0.27 \\
(0.55)\end{array}$ \\
\hline$N$ & 184 & 184 & 184 & 184 & 184 & 184 \\
\hline$R$-squared & 0.15 & 0.02 & 0.04 & 0.02 & 0.09 & 0.21 \\
\hline$R$-squared adjusted & 0.14 & 0.01 & 0.03 & 0.02 & 0.08 & 0.17 \\
\hline
\end{tabular}

* significant at $10 \%, * *$ significant at $5 \%$, *** significant at $1 \%$.

Robust standard errors are in parenthesis. 